\title{
Article \\ Hybridization of Saccharomyces cerevisiae Sourdough Strains with Cryotolerant Saccharomyces bayanus NBRC1948 as a Strategy to Increase Diversity of Strains Available for Lager Beer Fermentation
}

\author{
Martina Catallo ${ }^{1,+}+$ () , Fabrizio Iattici ${ }^{1,+}$, Cinzia L. Randazzo ${ }^{2}$, Cinzia Caggia ${ }^{2}$, Kristoffer Krogerus ${ }^{3}{ }^{(0)}$, \\ Frederico Magalhães ${ }^{3}$, Brian Gibson ${ }^{4}$ and Lisa Solieri ${ }^{1, * \text { (D) }}$ \\ 1 Department of Life Sciences, University of Modena and Reggio Emilia, via Amendola 2, \\ 42122 Reggio Emilia, Italy; 235140@studenti.unimore.it (M.C.); 204845@studenti.unimore.it (F.I.) \\ 2 Department of Agricultural, Food and Environment, University of Catania, via Santa Sofia, \\ 95123 Catania, Italy; cranda@unict.it (C.L.R.); ccaggia@unict.it (C.C.) \\ 3 VTT Technical Research Centre of Finland Ltd., Tietotie 2, P.O. Box 1000, FI-02044 VTT Espoo, Finland; \\ Kristoffer.Krogerus@vtt.fi (K.K.); Frederico.Magalhaes@vtt.fi (F.M.) \\ 4 Chair of Brewing and Beverage Technology, Technical University of Berlin, Seestraße 13, \\ 13353 Berlin, Germany; brian.gibson@tu-berlin.de \\ check for \\ updates \\ * Correspondence: lisa.solieri@unimore.it; Tel.: +39-0522-522026 \\ + These authors contribute equally to this work.
}

Citation: Catallo, M.; Iattici, F; Randazzo, C.L.; Caggia, C.; Krogerus, K.; Magalhães, F.; Gibson, B.; Solieri,

L. Hybridization of Saccharomyces cerevisiae Sourdough Strains with Cryotolerant Saccharomyces bayanus NBRC1948 as a Strategy to Increase Diversity of Strains Available for Lager Beer Fermentation. Microorganisms 2021, 9, 514. https:// doi.org/10.3390/microorganisms 9030514

Academic Editors: Marta Laranjo and Maurizio Ciani

Received: 3 December 2020

Accepted: 24 February 2021

Published: 2 March 2021

Publisher's Note: MDPI stays neutral with regard to jurisdictional claims in published maps and institutional affiliations.

Copyright: () 2021 by the authors. Licensee MDPI, Basel, Switzerland. This article is an open access article distributed under the terms and conditions of the Creative Commons Attribution (CC BY) license (https:// creativecommons.org/licenses/by/ $4.0 /)$.

Abstract: The search for novel brewing strains from non-brewing environments represents an emerging trend to increase genetic and phenotypic diversities in brewing yeast culture collections. Another valuable tool is hybridization, where beneficial traits of individual strains are combined in a single organism. This has been used successfully to create de novo hybrids from parental brewing strains by mimicking natural Saccharomyces cerevisiae ale $\times$ Saccharomyces eubayanus lager yeast hybrids. Here, we integrated both these approaches to create synthetic hybrids for lager fermentation using parental strains from niches other than beer. Using a phenotype-centered strategy, S. cerevisiae sourdough strains and the S. eubayanus $\times$ Saccharomyces uvarum strain NBRC1948 (also referred to as Saccharomyces bayanus) were chosen for their brewing aptitudes. We demonstrated that, in contrast to S. cerevisiae $\times S$. uvarum crosses, hybridization yield was positively affected by time of exposure to starvation, but not by staggered mating. In laboratory-scale fermentation trials at $20^{\circ} \mathrm{C}$, one triple S. cerevisiae $\times$ S. eubayanus $\times$ S. uvarum hybrid showed a heterotic phenotype compared with the parents. In $2 \mathrm{~L}$ wort fermentation trials at $12{ }^{\circ} \mathrm{C}$, this hybrid inherited the ability to consume efficiently maltotriose from NBRC1948 and, like the sourdough S. cerevisiae parent, produced appreciable levels of the positive aroma compounds 3-methylbutyl acetate (banana/pear), ethyl acetate (general fruit aroma) and ethyl hexanoate (green apple, aniseed, and cherry aroma). Based on these evidences, the phenotype-centered approach appears promising for designing de novo lager beer hybrids and may help to diversify aroma profiles in lager beer.

Keywords: sourdough yeasts; Saccharomyces bayanus; outcrossing; heterosis; aroma compounds; brewing

\section{Introduction}

Interspecific hybridization is an evolutionary force that shapes novel phenotypic and genomic profiles and may lead, via adaptive introgression or polyploidization, to the formation of new species [1,2]. In allodiploid hybrids, two divergent sub-genomes integrate and evolve within the same nucleus, with different possible phenotypic outcomes [3]. Genes that have never been tested together by natural selection may generate negative epistatic incompatibility, resulting in phenotypically intermediate hybrids that are suboptimally adapted compared to the parents $[4,5]$. An alternative outcome of hybridization, known as 
transgression or heterosis, involves the introgression of selectively favored alleles from one species into another [6]. These superior (over-dominant) combinations of heterozygous loci or the reciprocal complementation of harmful mutations can create hybrids that are able to thrive in new habitats relative to the parents [7].

The Saccharomyces genus encompasses many industrially important yeast species, including the model organism Saccharomyces cerevisiae. Interspecies sequence divergences range from $\sim 7 \%$ between the sister species Saccharomyces uvarum and Saccharomyces eubayanus [8] to $\sim 25 \%$ between $S$. cerevisiae and the members of the Saccharomyces bayanus species complex $[9,10]$. Despite these divergences, all the species tested to date can form F1 hybrids that reproduce asexually by mitosis and are isolated by postzygotic sterility barriers [11]. Natural S. cerevisiae $\times$ S. non-cerevisiae hybrids have been frequently isolated from stressful, industry-related niches, such as wine, beer and spirit fermentations, suggesting that hybridization could provide adaptation against stressors and could be successfully exploited in industrial innovation [11-15].

Lager beer, currently the most popular alcoholic beverage worldwide, is produced through wort fermentation at low temperatures (usually between 7 and $15^{\circ} \mathrm{C}$ ) by Saccharomyces pastorianus, an interspecific hybrid between the maltotriose-fermenting yeast $S$. cerevisiae and the cold-tolerant $S$. eubayanus [8,16-21]. Lager strains exhibit tolerance to low temperatures and efficient oligosaccharide utilization, two relevant traits in lager brewing environments $[20,22,23]$. Frohberg-type S. pastorianus strains and several Saaz-type S. pastorianus strains retain the ability to utilize maltotriose, the second major sugar in wort after maltose. By contrast, this trait can be absent in $S$. cerevisiae ale strains that are responsible for ale brewing [24]. Additionally, Saaz-type strains produce lower concentrations of aroma compounds like ethyl acetate, 3-methylbutanol, and 3-methylbutyl acetate than the more aroma-rich Frohberg yeasts [22].

Even if lager strains are the powerhouse of the modern brewing industry, their phenotypic potential is limited due to their containing genetic material from only two or three individual yeast lineages $[17,25,26]$. Therefore, the brewing industry looks toward novel brewing starters to meet the consumer demand for product diversification [27]. In response to this demand, several laboratory-made S. pastorianus-like hybrids were constructed between $S$. cerevisiae ale strains and S. eubayanus to expand the functional repertoire of lager strains $[21,28,29]$. These synthetic hybrids showed lager brewing performance similar to that of $S$. pastorianus strains, with respect to low-temperature tolerance and maltotriose utilization, but increased aroma diversity in beer compared to beers produced by traditional lager yeasts. However, since its discovery in 2011 in Patagonia [8], S. eubayanus is geographically restricted to North America [30], Asia [31], and New Zealand [32] and the low number of available strains hampers the potential of in vitro hybridization. Thus, alternative cold-tolerant Saccharomyces species, such as S. uvarum, Saccharomyces arboricola and Saccharomyces mikatae, were proposed in hybrid partnership with S. cerevisiae [33].

Hybridization can take place only between mating-competent cells. In conventional crossbreeding, sporulation has been utilized to generate mating-competent $M A T \mathrm{a}$ and $M A T \alpha$ haploid cells from non-mater $M A T a / \alpha$ diploid cells. In lager and ale strains polyploidy and aneuploidies prevent the progression of meiosis and/or creation of viable spores, limiting the utilization of this technique. Rare mating can bypass the low propensity of brewing yeasts to sporulate as it is based on spontaneous mating caused by loss of heterozygosity at the MAT locus [34]. However, interspecies hybridization occurs at a relatively low rate by rare mating and, like mass mating of spores, it requires preliminary time-consuming isolation of auxotrophic parental mutants [29,34,35]. The efficiency of interspecies mating can be improved by genetic modification (GM) techniques, for example, by $\mathrm{HO}$ deletion followed by interspecies crosses [36,37]. Alternatively, overexpression of the $\mathrm{HO}$ gene induces illegitimate mating type switching and produces mating-competent $M A T a / M A T a$ and MAT $\alpha / M A T \alpha$ diploids at high frequency [38,39]. These strategies produce GM hybrids that are still met with skepticism by consumers, who are reluctant to consume foods made via GM technology. 
Another solution to expand the portfolio of available brewing strains is to exploit strains from alternative food-related niches, such as sourdough, Brazilian spirits and sake [40-45]. However, these strains typically lack the ability to ferment wort at low temperature and have been proposed for ale brewing and other specialty beer styles [44]. In a previous study, for example, sourdough strains were proven to have good brewing aptitude and to produce "sahti" beer enriched in flavor compounds [45]. Here, we combined bioprospecting for novel yeasts from niches alternative to beer and hybridization and constructed interspecific hybrids between these $S$. cerevisiae sourdough strains and the cold-tolerant $S$. bayanus NBRC1948. This strain was recently demonstrated to be an $S$. eubayanus $\times S$. uvarum hybrid with some introgression from $S$. cerevisiae $[8,30,46,47]$. We evaluated the best conditions to increase hybridization yield using a marker-less spore-tospore method. We also compared the technological behavior of the obtained triple hybrids at laboratory scale in comparison to S. cerevisiae $\times$ S. uvarum hybrids. Finally, the potential application of the best $S$. cerevisiae $\times$ NBRC1948 hybrid candidate was demonstrated in two 2 L-scale fermentation trials.

\section{Materials and Methods}

\subsection{Strains, Culture Conditions and Chemicals}

Strains used in the present work are listed in Table 1. For growth, yeasts were cultured on YPDA medium ( $1 \% w / v$ yeast extract, $1 \% w / v$ peptone, $2 \% w / v$ dextrose, $2 \% w / v$ agar) for $48 \mathrm{~h}$ at $28{ }^{\circ} \mathrm{C}$ and then stored at $4{ }^{\circ} \mathrm{C}$ for the duration of work. For long-term storage, the strains were maintained at $-80{ }^{\circ} \mathrm{C}$ in YPD medium $(1 \% w / v$ yeast extract, $1 \% w / v$ peptone, $2 \% w / v$ dextrose) supplemented with $25 \%(v / v)$ glycerol as cryopreservation agent. All media and chemicals used in this study were purchased from Sigma Aldrich (St. Louis, MO, USA), except where differently indicated.

Table 1. Strains used in this work.

\begin{tabular}{|c|c|c|}
\hline Strains & Code & Origin/Characteristics \\
\hline \multirow{4}{*}{ S. cerevisiae } & Y15, Y17, Y18, Y19 & Sourdough of Maiorca flour (Maletto, CT) \\
\hline & Y21 & Sourdough of Maiorca flour (Castellammare, TP) \\
\hline & Y23 & Sourdough of Maiorca flour (Catania, CT) \\
\hline & Y26 & Sourdough of Maiorca flour (Balestrate, PA) \\
\hline & BY4741 & Euroscarf $/ M A T a$, his $3 \Delta 1$, leu $2 \Delta 0, \operatorname{met} 15 \Delta 0$, ura $3 \Delta 0$ \\
\hline & BY4742 & Euroscarf $/ M A T \alpha$, his $3 \Delta 1$, leu $2 \Delta 0$, lys $2 \Delta 0$, ura $3 \Delta 0$ \\
\hline & BY4743 & $\begin{array}{c}\text { Euroscarf/ MATa/MAT } \alpha, \text { his } 3 \Delta 1 / \text { his } 3 \Delta 1, \text { leu } 2 \Delta 0 / \text { leu } 2 \Delta 0, \\
\text { lys } 2 \Delta 0 / \operatorname{lys} 2 \Delta 0, \text { ura } \Delta 0 / \text { ura } \Delta 0\end{array}$ \\
\hline & 3002 & Wine [48] \\
\hline S. pastorianus & Fermolager W & Lager Frohberg yeast (AEB spa, Brescia) \\
\hline \multirow[t]{2}{*}{ S. uvarum } & $\mathrm{RC} 2-10$ & $\begin{array}{l}\text { Grape fermenting yeast (Alsace); kindly provided by } \\
\text { Philippe Marullo }\end{array}$ \\
\hline & 7877 & wine; DIROVAL ${ }^{1}$ collection \\
\hline S. cerevisiae $\times$ S. uvarum hybrid & LS3 & [49] \\
\hline S. bayanus & NBRC1948 & - \\
\hline S. cariocanus & CBS8841 & Drosophila sp. (Rio de Janeiro, Brazil) \\
\hline
\end{tabular}

${ }^{1}$ DIPROVAL, Dipartimento di Protezione e Valorizzazione Agroalimentare, University of Bologna.

Strains used in the present work are listed in Table 1. For growth, yeasts were cultured on YPDA medium ( $1 \% w / v$ yeast extract, $1 \% w / v$ peptone, $2 \% w / v$ dextrose, $2 \% w / v$ agar) for $48 \mathrm{~h}$ at $28{ }^{\circ} \mathrm{C}$ and then stored at $4{ }^{\circ} \mathrm{C}$ for the duration of work. For long-term storage, the strains were maintained at $-80^{\circ} \mathrm{C}$ in YPD medium $(1 \% w / v$ yeast extract, $1 \% w / v$ peptone, 
$2 \% w / v$ dextrose) supplemented with $25 \%(v / v)$ glycerol as cryopreservation agent. All media and chemicals used in this study were purchased from Sigma Aldrich (St. Louis, MO, USA), except where differently indicated.

\subsection{Maltose and Glucose Consumpion Tests}

Maltose and glucose fermentation tests were carried out utilizing the procedure described by Kurtzman et al. [50]. Briefly, basal medium $(0.45 \% w / v$ yeast extract, $0.75 \% w / v$ peptone and $0.0048 \% w / v$ bromothymol blue as $\mathrm{pH}$ indicator) was previously autoclaved, then sugar stock solution was added to a final concentration of $2 \%(w / v)$, and dispensed in test tubes with screw caps and containing inverted Durham tubes. The tubes were inoculated with $10 \mu \mathrm{L}$ of microbial suspension, kept at $28^{\circ} \mathrm{C}$ and monitored for 21 days for the production of gas. Scores were attributed according to Kurtzman et al. [50] as follows: + , strongly positive, insert filled within 7 days; s, slowly positive, insert slowly filled after more than 7 days; - , no gas production.

Growth ability was also evaluated by inoculating each strain at the final concentration of $10^{5}$ cell $/ \mathrm{mL}$ in YNB medium $(0.67 \% w / v$ Yeast Nitrogen Base with amino acids and ammonium sulfate, BD Difco, Sparks, MD) supplemented with $2 \%(w / v)$ either glucose or maltose as carbon sources. Optical absorbance was measured at $600 \mathrm{~nm}$ after $48 \mathrm{~h}$ of incubation at $25^{\circ} \mathrm{C}$ under shaking conditions $(150 \mathrm{rpm})$ in three independent replicates [40].

\subsection{Sporulation Efficiency, Spore Viability and Generation of Spore Clones}

For sporulation tests, yeasts were sub-cultured in YPDA medium at $28{ }^{\circ} \mathrm{C}$ for $24 \mathrm{~h}$, transferred to sporulation medium (ACM; $0.5 \% w / v$ sodium acetate, $2 \% w / v$ agar; $\mathrm{pH} 6.5$ ) and incubated at $28{ }^{\circ} \mathrm{C}$ for a period of 14 days. Asci formation was microscopically checked after 3, 7, and 14 days and scored according to Kurtzman et al. [50].

Sporulation efficiency was determined by resuspending cells/asci mixtures from sporulation medium into physiological water (approximately $1 \times 10 \mu \mathrm{L}$-loop into $1 \mathrm{~mL}$ physiological water). The total number of cells and the number of asci were counted in a Bürker chamber under an optical microscope (Carl Zeiss, Oberkochen, Germany). Sporulation efficiency was calculated as follows:

$$
\text { Sporulation } \%=\left[\left(\mathrm{n}^{\circ} \text { asci }\right) /\left(\mathrm{n}^{\circ} \text { asci }+\mathrm{n}^{\circ} \text { cells }\right)\right] \times 100 \text {. }
$$

For each strain, at least six tetrad asci were gently digested with $0.2 \mathrm{U}$ of Zymolyase $20 \mathrm{~T}$ (AMSBIO, Abingdon, UK) for $20 \mathrm{~min}$ at RT and dissected on YPDA plates using a Singer MSM Manual micromanipulator device (Singer Instruments, Somerset, UK), according to [49]. Single spores were incubated at $28^{\circ} \mathrm{C}$ for $48 \mathrm{~h}$. Spore viability was calculated as follows:

$$
\text { Spore Viability } \%=\left(\mathrm{n}^{\circ} \text { of vital spores } / \mathrm{n}^{\circ} \text { of dissected spores }\right) \times 100
$$

The obtained spore clones were streaked on YPDA plates and stored at $4{ }^{\circ} \mathrm{C}$ for the duration of work.

\subsection{Mating Competence Assay}

Spore clones were tested for mating competence in mixture cultures with either BY4741 (MATa) or BY4742 (MAT $\alpha$ ) mating testers on YPDA plates according to Kurtzman et al. [50]. Plates were incubated at $28^{\circ} \mathrm{C}$ and conjugative bridges were checked at 8,24 and $48 \mathrm{~h}$ after mixing the cultures.

\subsection{Construction of Inter-Specific Hybrids}

Hybrids were generated by the spore-to-spore mating method [49], with the exception of the $S$. cerevisiae $\times$ Saccharomyces cariocanus cross, where $S$. cerevisiae vegetative haploid monospore clones were used instead of spores. A scheme of hybridization strategy is reported in Figure 1. 


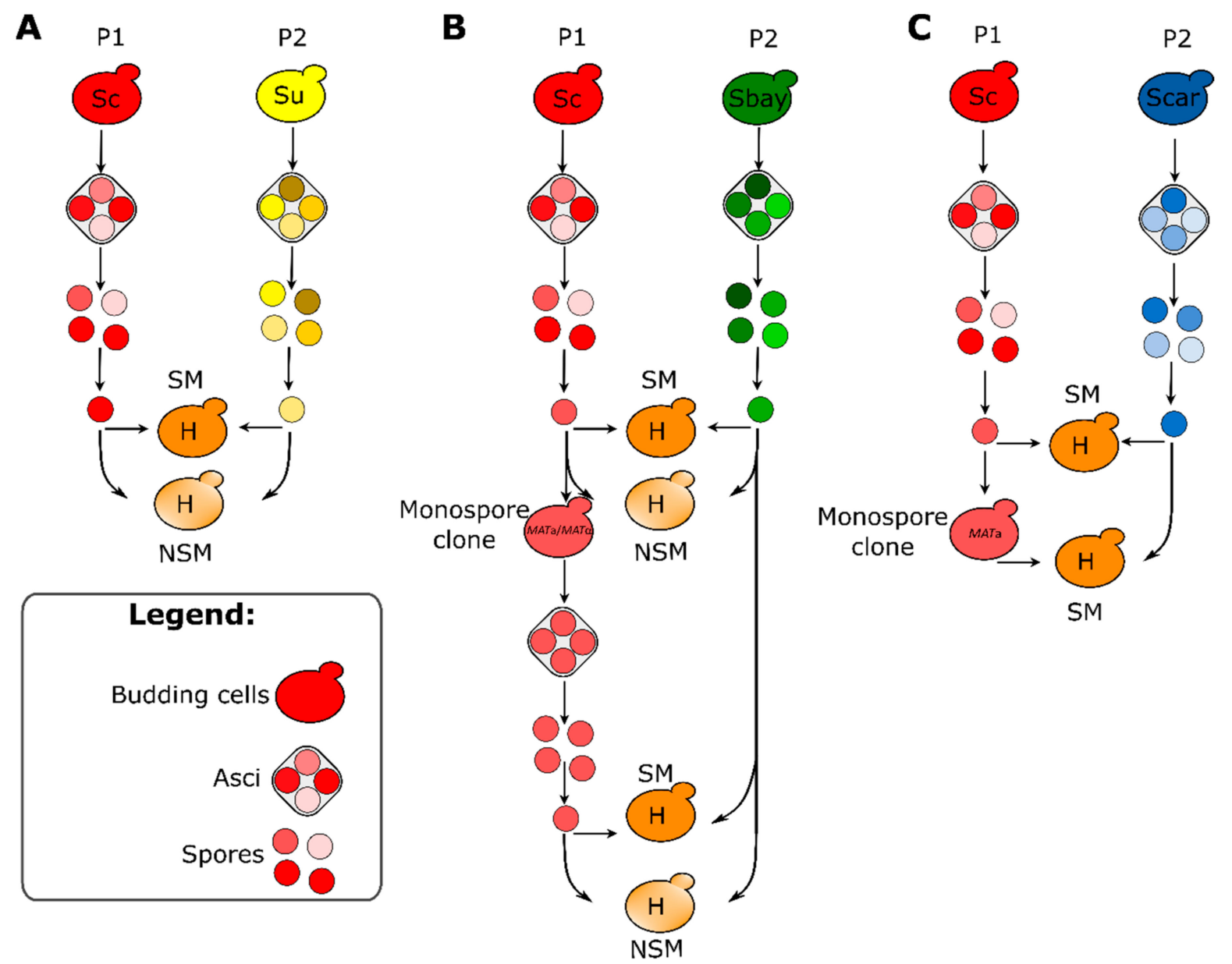

Figure 1. Overview of hybridization scheme used in the present study. Three crosses were attempted: (A) Saccharomyces cerevisiae $\times$ Saccharomyces uvarum RC2-10, (B) S. cerevisiae $\times$ Saccharomyces bayanus NBRC1948 and (C) S. cerevisiae $\times$ Saccharomyces cariocanus CBS8841. S. cerevisiae $\times$ S. uvarum RC2-10 and S. cerevisiae $\times$ S. bayanus NBRC1948 crosses were carried out in staggered mating (SM) and non-staggered mating (NSM), while S. cerevisiae $\times$ S. cariocanus cross in SM only. Mating involved spores from wild-type strains and/or spores from monospore clones in S. cerevisiae $\times$ Scheme 2 . and S. cerevisiae $\times$ S. bayanus NBRC1948 crosses. Mating involved either spores from wild-type strains or mating-competent cells in S. cerevisiae $\times$ S. cariocanus CBS8841 cross. Abbreviations: SM, staggered mating; NSM, non-staggered mating; Sc, S. cerevisiae; Su, S. uvarum; Sbay, S. bayanus; Scar, S. cariocanus; P1, parental strain 1; P2, parental strain 2.

In detail, for each mating trial, at least three independent crosses were attempted. $S$. cerevisiae has been reported to have a germination time lower than other Saccharomyces non-cerevisiae species and this difference negatively impacts interspecies mating [51]. In non-staggered mating (NSM) trials both parental asci were dissected on YPDA mating plates and spores were immediately placed in contact with one another. In staggered mating (SM) trials, S. cerevisiae asci were dissected $4 \mathrm{~h}$ later than the Saccharomyces noncerevisiae asci in order to discern whether hybridization yield increases in SM compared to NSM assays. Mating plates were incubated at $30^{\circ} \mathrm{C}$ for $3-4 \mathrm{~h}$ and hybrid candidates were streaked at least in duplicate in YPDA medium and then cultured in YPD broth for approximatively 20 generations in order to assure genetic stability of the new hybrids. Finally, hybrids were cryo-preserved at $-80{ }^{\circ} \mathrm{C}$ in YPD medium supplemented with $25 \%$ $(w / v)$ glycerol.

Hybridization frequency was calculated as follows:

Hybridization frequency $(\%)=\left[\left(n^{\circ}\right.\right.$ of positive hybrids scored $/ \mathrm{n}^{\circ}$ of total crosses attempted $\left.)\right] \times 100$. 
To test the effect of residence time in starvation conditions on mating propensity, cells were incubated on ACM medium and the plates containing spores were stored at $4{ }^{\circ} \mathrm{C}$ for 105 days. Asci age was calculated in days starting from the plating on sporulation medium. Mating propensity was calculated by spore-to-spore mating after 35 and 105 days of residence on ACM, respectively.

\subsection{Molecular Methods}

Yeast DNA was extracted from single colonies with the lithium acetate-SDS method [52]. $M A T$ genotyping was carried out on sourdough strains and their monospore clones using primers described by Huxley et al. [53]. Strains BY4742 (MAT $\alpha)$ and BY4743 (MATa) were used as internal controls. Hybrids were validated by PCR-RFLP analysis of ITS1 spacer with HaeIII enzyme (Thermo Fisher Scientific, Waltham, MA, USA) [54] and PCR amplifications of FSY1 and MEX67 genes using species-specific primers [55]. Genotyping of hybrids after genome stabilization was done by (GTG) $)_{5}$ fingerprinting assay according to Dakal et al. [56]. All PCR reactions were carried out in a T100 Thermal Cycler (Bio-Rad, Hercules, CA, USA). All PCR mixtures were performed in $20 \mu \mathrm{L}$ of final volume containing $1 \mu \mathrm{L}$ of colony DNA as template, $0.4 \mu \mathrm{M}$ of each primer, $200 \mu \mathrm{M}$ each dNTP, and $0.5 \mathrm{U}$ DreamTaq DNA polymerase (Thermo Fisher Scientific, Waltham, MA, USA) according to the manufacturer's instructions.

\subsection{Wort Fermentations}

Micro-scale trials were carried out according to Catallo et al. [45]. Fermentations were performed in duplicate with $100 \mathrm{~mL}$ of $15^{\circ}$ Plato $\left({ }^{\circ} \mathrm{P}\right)$ all-malt wort $(96.36 \mathrm{~g} / \mathrm{L}$ maltose and $40.18 \mathrm{~g} / \mathrm{L}$ maltotriose) in $250 \mathrm{~mL}$ Erlenmeyer flasks, without agitation. Airlocks containing $2 \mathrm{~mL}$ of $85 \%$ glycerol were used to seal the flasks. Weight loss of the flasks due to $\mathrm{CO}_{2}$ release was measured with an analytical balance and used to monitor fermentation progress. A "neutral" fermentation temperature of $20^{\circ} \mathrm{C}$ was chosen to support growth of all strains. Final measurements and samples were taken after 14 days. Ethanol concentration and $\mathrm{pH}$ values were determined from the centrifuged and degassed fermentation samples using an Anton Paar Density Meter DMA 5000 M with Alcolyzer Beer ME and pH ME modules (Anton Paar GmbH, Graz, Austria). After washing with deionized $\mathrm{H}_{2} \mathrm{O}$, each yeast pellet was transferred to a pre-weighed porcelain crucible, dried overnight at $105{ }^{\circ} \mathrm{C}$ and weighed to determine the dry mass content. Viability percentage was determined in a NucleoCounter ${ }^{\circledR}$ YC- $100^{\mathrm{TM}}$ as previously reported [57] and calculated as follows:

$$
\% \text { viability }=[(\text { total cells }- \text { dead cells }) / \text { total cells }] \times 100 \text {. }
$$

Fermentation curves were modeled based on the weight loss trend over time using the "grofit"-package for R [58]. Maximum rate of fermentation $(\mu)$ and maximum fermentation efficiency (total amount of $\mathrm{CO}_{2}$ released at the end of the fermentation; $\mathrm{A}$ ) were determined using the spline-fitting method in "grofit".

For 2 L-scale fermentations, an inoculation loop was first used to transfer a small amount of yeast to $50 \mathrm{~mL}$ YPD medium and propagated under aerobic conditions on a shaker $(100 \mathrm{rpm})$ at $20^{\circ} \mathrm{C}$. After propagation overnight, the cells were washed in sterile Milli-Q-filtered water and re-suspended to achieve a $20 \%$ slurry (200 g fresh yeast/L). This slurry was used to inoculate $1 \mathrm{~L}$ of all-malt $15^{\circ} \mathrm{P}$ wort in a $2 \mathrm{~L}$ Erlenmeyer flask at a pitching rate of $1 \mathrm{~g} / \mathrm{L}$. After a two-day incubation period at $20^{\circ} \mathrm{C}$ and shaking $(100 \mathrm{rpm})$, the flask contents were centrifuged and yeast was again washed and re-suspended to achieve a $20 \%$ slurry. In this case the fermented wort, rather than water, was used for resuspension of cells. This slurry was used to inoculate $1.5 \mathrm{~L}$ of $15^{\circ} \mathrm{P}$ wort within $2 \mathrm{~L}$-scale sterile stainless steel cylindroconical vessels at a pitching rate of $1 \mathrm{~g} / \mathrm{L}$. Fermentations were conducted at $12{ }^{\circ} \mathrm{C}$, as similarly low temperatures are typical for the production of lager-style beer, and low-temperature tolerance is an essential criterion for the selection of prospective lager brewing yeasts. Samples were taken aseptically throughout the fermentation period. 
Samples for yeast-derived flavor compound determinations were drawn from the beer when fermentations were ended and immediately frozen until the analysis.

\subsection{Chemical Analysis}

Yeast-derived flavor compounds were determined by headspace gas chromatography with flame ionization detection (HS-GC-FID). Briefly, samples of $4 \mathrm{~mL}$ were filtered $(0.45 \mu \mathrm{m})$, incubated at $60^{\circ} \mathrm{C}$ for $30 \mathrm{~min}$, and then $1 \mathrm{~mL}$ of gas phase was injected (split mode; $225^{\circ} \mathrm{C}$; split flow of $30 \mathrm{~mL} / \mathrm{min}$ ) into a gas chromatograph equipped with an FID detector and headspace autosampler (Agilent 7890 Series; Palo Alto, CA, USA). Analytes were separated on a HP- 5 capillary column $(50 \mathrm{~m} \times 320 \mu \mathrm{m} \times 1.05 \mu \mathrm{m}$ column, Agilent, Palo Alto, CA USA). The carrier gas was helium (constant flow of $1.4 \mathrm{~mL} / \mathrm{min}$ ). The temperature program was $50^{\circ} \mathrm{C}$ for $3 \mathrm{~min}, 10^{\circ} \mathrm{C} / \mathrm{min}$ to $100^{\circ} \mathrm{C}, 5^{\circ} \mathrm{C} / \mathrm{min}$ to $140^{\circ} \mathrm{C}, 15^{\circ} \mathrm{C} / \mathrm{min}$ to $260^{\circ} \mathrm{C}$ and then isothermal for $1 \mathrm{~min}$. Compounds were identified by comparison with authentic standards and were quantified using standard curves. 1-Butanol was used as internal standard $(246 \mathrm{mg} / \mathrm{L})$.

For sugar analysis, the samples collected at the end of the fermentation were centrifuged and the supernatants were filtered $(0.45 \mu \mathrm{m})$ prior to storing in a freezer $\left(-23^{\circ} \mathrm{C}\right)$. Sugar content of wort was analyzed by HPLC. A Waters 2695 Separation Module and Waters System Interphase Module liquid chromatograph coupled with a Waters 2414 differential refractometer (Waters Co., Milford, MA, USA) was used. An Aminex HPX-87H Organic Acid Analysis Column ( $300 \times 7.8 \mathrm{~mm}$; Bio-Rad, Hercules, CA, USA) was equilibrated with $5 \mathrm{mM} \mathrm{H}_{2} \mathrm{SO}_{4}$ (Titrisol, Merck, Germany) in water at $55^{\circ} \mathrm{C}$, and samples were eluted with $5 \mathrm{mM} \mathrm{H}_{2} \mathrm{SO}_{4}$ in water at a $0.3 \mathrm{~mL} / \mathrm{min}$ flow rate.

\subsection{Statistical Analysis}

Data on maltose and glucose consumption and on $2 \mathrm{~L}$ wort fermentation were statistically analyzed with two-way ANOVA $(p<0.05)$ followed by a Tukey's multiple comparisons test. Statistical analysis was performed on kinetics parameters and aroma concentrations with a one-way ANOVA and Tukey's test. All analyses were performed using GraphPad Prism software (GraphPad Software, Inc, San Diego, CA, USA). $p$ values $<0.05$ were considered as statistically significant.

\section{Results}

\subsection{Maltose Fermentation Screening}

Maltose is one of the main fermentable sugars in sourdough because it is constantly generated by the degrading activity of amylase on starch [59]. Maltose represents $60 \%$ of carbohydrates in wort, a complex substrate also containing $10 \%$ of glucose and $25 \%$ of maltotriose as fermentable sugars [60]. Sourdough strains were proven to exhibit a good brewing aptitude [45] and could be promising parental candidates for brewing hybrid construction with Saccharomyces non-cerevisiae cryotolerant species. Fermentation tests showed that all S. cerevisiae strains, S. uvarum RC2-10, S. bayanus NBRC1948 ferment maltose, but not $S$. cariocanus CBS8841 (Table 2).

To assess inter-strain differences in growth on maltose, biomass was also tested as absorbance after $48 \mathrm{~h}$ of fermentation in maltose and glucose-containing media. S. cerevisiae Y19, Y21, Y23 and Y26 were the best maltose-fermenting strains, while Y17 exhibited a slow-growing phenotype both in glucose and maltose-supplemented media. Strains Y19 and Y23 did not show any significant diversity in maltose and glucose consumption $(p<0.05)$ (Table 2). 
Table 2. Maltose consumption tests. The results of fermentation tests are scored according to Kurtzman et al. [50] as follows: + , strongly positive; s, slowly positive; -, no gas production. Optical density at $600 \mathrm{~nm}\left(\mathrm{OD}_{600 \mathrm{~nm}}\right)$ was evaluated after $48 \mathrm{~h}$ of fermentation in medium containing either glucose or maltose. Different superscript letters indicate significant differences $(p<0.05)$ in the same column, while different symbols $\left({ }^{*}\right.$ and $\left.\S\right)$ indicate significant differences in the same raw, as determined by ANOVA followed by Tukey HSD test. Superscript letters were attributed as follows: the highest value was marked as " $a$," the next value that is significantly different can be " $b$," and so on. Abbreviation: nd, not determined.

\begin{tabular}{|c|c|c|c|c|}
\hline \multirow{2}{*}{ Species } & \multirow{2}{*}{ Strain } & \multirow{2}{*}{ Fermentation Assay } & \multicolumn{2}{|c|}{ Optical Density $\left(\mathrm{OD}_{600 \mathrm{~nm}}\right)$} \\
\hline & & & Glucose $(2 \% w / v)$ & Maltose $(2 \% v / w)$ \\
\hline \multirow[t]{7}{*}{ S. cerevisiae } & Y15 & $\mathrm{s}$ & $1.402^{b, *} \pm 0.031$ & $1.098^{\mathrm{b}, \S} \pm 0.02$ \\
\hline & Y17 & $\mathrm{s}$ & $1.145^{c, *} \pm 0.016$ & $0.677^{c, \S} \pm 0.06$ \\
\hline & Y18 & $\mathrm{s}$ & $1.438^{b, *} \pm 0.042$ & $1.029^{b, \S} \pm 0.093$ \\
\hline & Y19 & + & $1.428^{b, *} \pm 0.016$ & $1.257^{\mathrm{a}, \mathrm{b}, *} \pm 0.046$ \\
\hline & $\mathrm{Y} 21$ & $\mathrm{~s}$ & $1.970^{a, *} \pm 0.203$ & $1.412^{\mathrm{a}, \S} \pm 0.05$ \\
\hline & $\mathrm{Y} 23$ & $\mathrm{~s}$ & $1.551^{\mathrm{b}, *} \pm 0.228$ & $1.495^{\mathrm{a}, *} \pm 0.119$ \\
\hline & Y26 & + & $1.687^{\mathrm{a}, *} \pm 0.12$ & $1.252^{\mathrm{a}, \mathrm{b}, \S} \pm 0.101$ \\
\hline S. uvarum & RC2-10 & $\mathrm{s}$ & nd & nd \\
\hline S. bayanus & NBRC1948 & $\mathrm{s}$ & nd & nd \\
\hline S. cariocanus & CBS8841 & - & nd & nd \\
\hline
\end{tabular}

\subsection{Sporulation Efficiency and Spore Viability}

In order to generate artificial hybrids by spore-to-spore mating, parental strains should sporulate and produce viable spores. Table 3 shows that the majority of strains sporulated after 3 days of incubation with a sporulation efficiency ranging from 17.2 to $35.9 \%$. S. cerevisiae Y17 was the best sporulating strain $(35.9 \%)$, while three strains, including $S$. uvarum RC2-10, and S. cerevisiae Y18 and Y26, showed an efficiency lower than $25 \%$. Despite Y17 having the highest sporulation efficiency, it showed the lowest spore viability $(29.2 \%)$, while other yeasts had spore viability values ranging from $45.8 \%$ for strains $Y 18$ and Y19 to $66.7 \%$ for strain Y23. Overall, S. cerevisiae Y15, Y19, Y21 and Y23 exhibited the best phenotype in terms of both sporulation efficiency and spore viability. Three of them (Y19, Y21 and Y23) were the most suitable to grow on maltose as carbon source.

Table 3. Sporulation efficiency, spore viability and MAT genotype. Strains sporulating after 3 and 7 days were scored as + and w (weak), respectively. Sporulation efficiency was determined as the mean of two independent replicates, while viability was calculated considering the dissection of six tetrads for each strain. All values of sporulation efficiency were statistically different based on one-way ANOVA. Abbreviation: nd, not determined.

\begin{tabular}{|c|c|c|c|c|c|}
\hline Species & Strain Code & Sporulation & $\begin{array}{c}\text { Sporulation } \\
\text { Efficiency (\%) }\end{array}$ & Viability (\%) & MAT Genotype \\
\hline \multirow[t]{7}{*}{ S. cerevisiae } & Y15 & + & $32.9 \pm 0.07$ & 47.2 & $M A T a / M A T \alpha$ \\
\hline & Y17 & + & $35.9 \pm 0.04$ & 29.2 & $\begin{array}{l}M A T \mathrm{a} / M A T \alpha \\
M A T \mathrm{a} / M A T \alpha\end{array}$ \\
\hline & Y18 & + & $19.0 \pm 0.04$ & 45.8 & $M A T a / M A T \alpha$ \\
\hline & Y19 & + & $35.4 \pm 0.00$ & 45.8 & $M A T a / M A T \alpha$ \\
\hline & $\mathrm{Y} 21$ & + & $34.5 \pm 0.04$ & 54.2 & $M A T a / M A T \alpha$ \\
\hline & $\mathrm{Y} 23$ & + & $32.1 \pm 0.04$ & 66.7 & $M A T \mathrm{a} / M A T \alpha$ \\
\hline & $\mathrm{Y} 26$ & $\mathrm{w}$ & $17.2 \pm 0.01$ & 54.2 & $M A T a / M A T \alpha$ \\
\hline S. uvarum & RC2-10 & $\mathrm{w}$ & $20.4 \pm 0.01$ & nd & nd \\
\hline S. bayanus & NBRC1948 & $\mathrm{w}$ & $30.9 \pm 0.02$ & nd & nd \\
\hline S. cariocanus & CBS8841 & + & nd & nd & nd \\
\hline
\end{tabular}




\subsection{MAT Genotyping of Strains and Their Meiotic Segregants}

Yeasts with MATa/MAT $\alpha$ genotype are presumed to be non-haploid strains [61]. S. cerevisiae sourdough strains had a MATa/MAT $\alpha$ genotype (Table 3): this genotype could be congruent with a diploid status, but aneuploidy and/or polyploidy (such as MATa/MATa/MATa/MAT $\alpha, M A T \alpha / M A T \alpha / M A T \alpha / M A T a$ and MAT $\alpha / M A T \alpha / M A T a /$ $M A T a)$ cannot be excluded.

Homothallism/heterothallism are critical factors that affect mating efficiency and hybridization yield [62]. Homothallic $\mathrm{HO} / \mathrm{HO}$ diploid strains would result in tetrads with only diploid MATa/MAT $\alpha$ spores, while heterothallic ho / ho strains would be associated with MATa and MAT $\alpha$ progenies in a maximal ratio of 2:2, excluding death events. Conversely, heterozygous $H O / h o$ strains can generate spores with either diploid or haploid genomes in a typical ratio of 2:2. To unravel the ability of sourdough strains to switch mating type, MAT multiplex PCR was also carried out on their meiotic segregants. All strains yielded the MATa/MAT $\alpha$ segregant progenies with a frequency ranging from $46 \%$ to $73 \%$ (Figure 2). We also found MATa segregant clones (Figure 2) unable to sporulate and able to mate with mating tester BY4742 (MAT $\alpha$ ) (data not shown). All these results support that the MATa meiotic segregants are mating-competent and therefore suitable for outcrossing. Interestingly, $M A T \alpha$ clones were rarely dissected, with the exception of two tetrads from strains Y18 and Y19 (Figure 2). As BY4742 (MAT $\alpha$ ) was used as a positive control in PCR amplification of the MAT $\alpha$ locus, we supposed that the majority of MAT $\alpha$ haploid cells might be non-viable. Analysis of progeny distributions within each tetrad showed that diploid MATa $/ M A T \alpha$ occurred no more than twice for tetrad (Figure 2). The coexistence of MATa/MAT $\alpha$ and MATa spores in the same tetrad is congruent with a $H O / h o$ genotype for the tested strains, suggesting that they are suitable for spore-to-spore mating.

\subsection{Hybrid Construction}

Sourdough strains Y15, Y19, Y21 and Y23 were chosen for hybrid construction on the basis of maltose consumption, sporulation efficiency and spore viability. Strain NBRC1948 (referred to as Sbay for convenience) was chosen for its peculiar genetic content, as being an S. eubayanus $\times$ S. uvarum hybrid with introgressed segments from S. cerevisiae [30]. S. uvarum RC2-10 (referred to as Su for convenience) and S. cariocanus CBS8841 (referred to as Scar for convenience) were chosen as alternative cryotolerant parents for comparative purposes.

Out of 190 attempted crosses, a total of 46 hybrids were generated and validated by molecular ITS1 PCR-RFLP assay and species-specific PCR (Supplementary Figure S1). Hybrid yield was higher than $22 \%$ for most of the cases (Table 4). Out of 46 novel hybrids, three were between S. cerevisiae and S. cariocanus ( $\mathrm{Sc} \times \mathrm{Scar}$ ), 11 between $S$. cerevisiae and S. uvarum $(\mathrm{Sc} \times \mathrm{Su})$, and 32 between $S$. cerevisiae and S. bayanus $(\mathrm{Sc} \times \mathrm{Sbay})$. All three Sc $\times$ Scar hybrids, as well as three Sc $\times$ Su and 11 Sc $\times$ Sbay randomly selected hybrids were tested for sporulation. As opposed to Sc $\times$ Su hybrids, all the Sc $\times$ Sbay and Sc $\times$ Scar hybrids were able to sporulate (Supplementary Table S1).

Differences in germination time are some of the main prezygotic barriers among Saccharomyces species [63], so we performed pilot mating experiments under NSM and $\mathrm{SM}$ conditions. In the case of the S. cerevisiae $\times$ S. uvarum cross, we first attempted to gain hybrids by SM, which was previously reported to enhance hybridization yield [64]. Under $\mathrm{SM}$, hybridization frequency was $27 \%$ for $\mathrm{Y} 23 \times \mathrm{RC} 2-10$ crosses, whereas no hybrids were obtained when spores of S. cerevisiae Y15 were mated with spores of S. uvarum RC2-10 (Table 4). When the same strain pairs were tested under NSM conditions, hybrid frequency ranged between 20 and 31\%, suggesting that differences in germination time were not relevant for these parental strains. In mating trials between S. cerevisiae and S. bayanus, SM did not enhance hybridization frequency compared with the NSM condition (Table 4). 


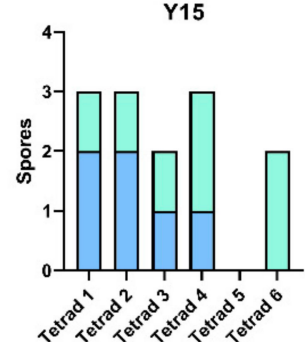

Y17

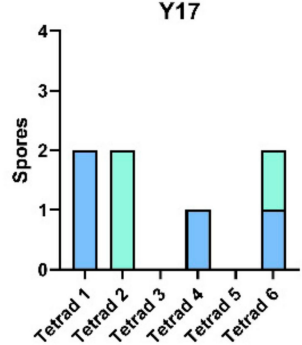

Y18

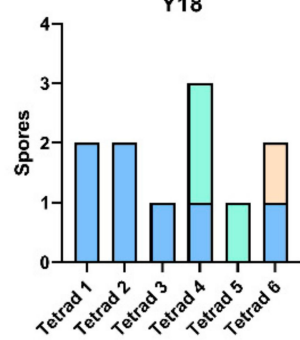

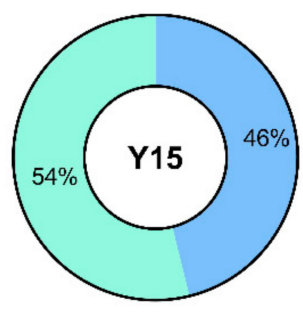
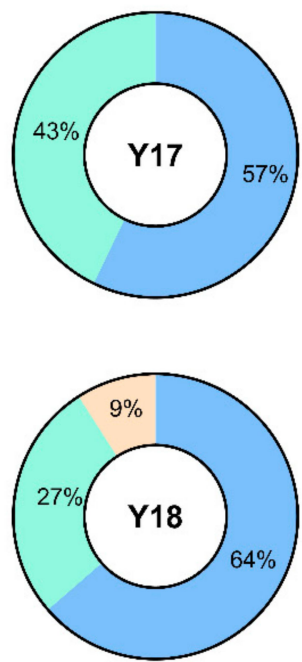
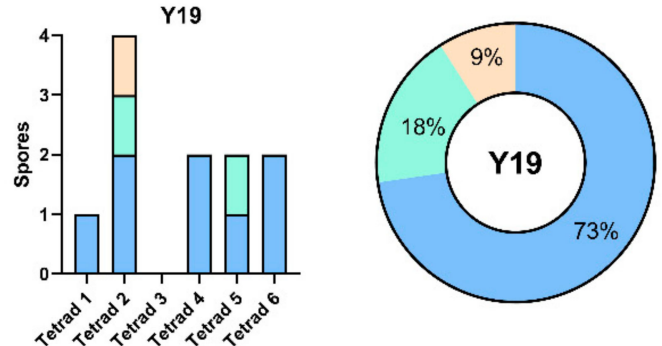

Y21
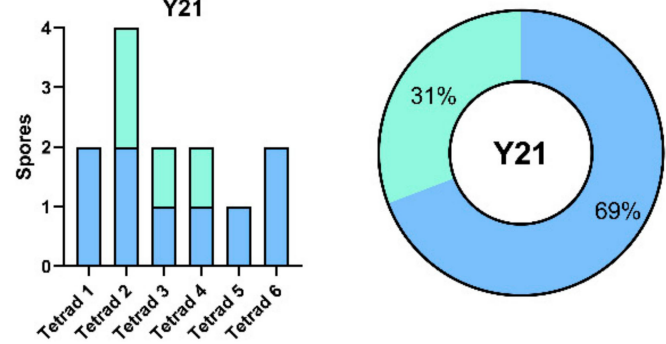

Y23
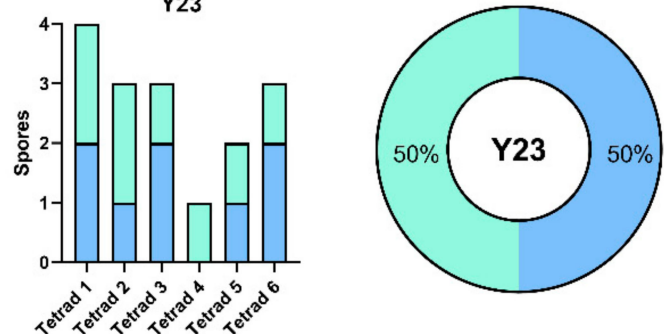

Y26
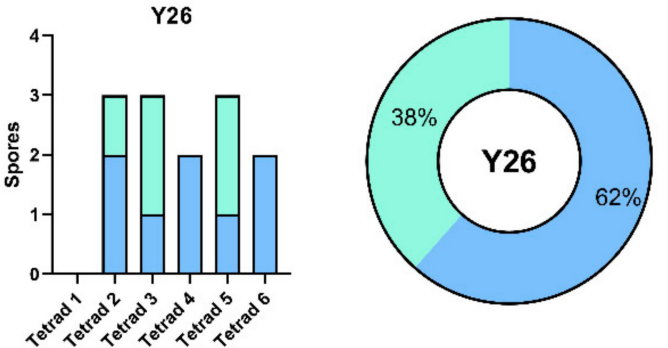

$\square$ Diploid

$\square$ Haploid a

$\square$ Haploid a

Figure 2. Mating types of meiotic segregants from S. cerevisiae sourdough strains. For every strain, column graph (left) shows MAT loci segregation in single meiotic events, while pie chart (right) Table.

Table 4. Hybridization frequency (\% values) in staggered (SM) and non-staggered (NSM) mating trials. Abbreviations: SM, staggered mating; NSM, non-staggered mating; Sc, S. cerevisiae; Su, S. uvarum; Sbay, S. bayanus; Scar, S. cariocanus; nd, not determined.

\begin{tabular}{cccc}
\hline \multirow{2}{*}{ Parental Strains } & Type of Mating & Hybridization Frequency (\%) \\
\cline { 3 - 4 } & & SM & NSM \\
\hline Y15 $\times$ RC2-10 & Sc $\times$ Su direct spore-to-spore & 0 & 23 \\
Y23 $\times$ RC2-10 & Sc $\times$ Su direct spore-to-spore & 27 & 31 \\
Y15.2B $\times$ NBRC1948 & Sc segregant spore-to-Sbay spore & 10 & 41 \\
Y19 $\times$ NBRC1948 & Sc $\times$ Sbay direct spore-to-spore & 31 & 32 \\
Y21 $\times$ NBRC1948 & Sc $\times$ Sbay direct spore-to-spore & 13 & nd \\
Y19 $\times$ CBS8841 & Sc $\times$ Scar direct spore-to-spore & 22 & nd \\
Y19.5A $\times$ CBS8841 & Sc cell-to-Scar spore & 9 & \\
\hline
\end{tabular}

S. cariocanus represents a particular S. paradoxus strain harboring four chromosomal translocations and which, consequently, is not interfertile with the S. paradoxus tester 
strain [18]. In S. cerevisiae $\times$ S. cariocanus crosses, we considered two individual interspecific pairings under SM, which was previously demonstrated to increase hybridization rates in S. cerevisiae $\times$ S. paradoxus mating trials [51]. Either spores from strain Y19 $(M A T a / M A T \alpha)$ or vegetative cells of the haploid monospore clone Y19.5A (MATa) were mated with spores from $S$. cariocanus CBS8841. By using $4 \mathrm{~h}$ of staggering time in both crosses, we obtained hybrid yields of 22\% and 9\% for Y19 $\times$ CBS8841 (spore-to-spore mating) and Y19.5A × CBS8841 (cell-to-spore mating), respectively.

During these pilot experiments, we also observed that asci maintained on ACM plates for long times (approximately 105 days) resulted in spores particularly prone to mate. To corroborate this observation, we performed Sc $\times$ Su and Sc $\times$ Sbay mating trials with both spores on ACM for 35 days and spores on ACM for 105 days. As shown in Table 5, old spores resulted in hybridization frequency higher than young spores, suggesting that spore age affects hybridization yield more than SM conditions.

Table 5. Effect of spore residence in ACM on hybridization frequency. Abbreviations: SM, staggered mating; NSM, non-staggered mating; Sc, S. cerevisiae; Su, S. uvarum; Sbay, S. bayanus.

\begin{tabular}{cccccc}
\hline \multirow{2}{*}{ Parental Strains } & Type of Mating & \multicolumn{3}{c}{ Hybridization Frequency (\%) } \\
\cline { 3 - 6 } & & \multicolumn{2}{c}{ 35 Days Age } & \multicolumn{2}{c}{ 105 Days Age } \\
\cline { 3 - 6 } & & SM & NSM & SM & NSM \\
\hline Y15 $\times$ RC2-10 & Sc $\times$ Su direct spore-to-spore & 0 & 23 & 10 & 28 \\
Y21 $\times$ NBRC1948 & Sc $\times$ Sbay direct spore-to-spore & 13 & 33 & 39 & 55 \\
\hline
\end{tabular}

\subsection{Laboratory-Scale Wort Fermentation}

Novel Sc $\times$ Sbay $(Y 15.2 B \times$ NBRC1948, Y19 $\times$ NBRC1948 and Y21 $\times$ NBRC 1948) and $\mathrm{Sc} \times \mathrm{Su}(\mathrm{Y} 23 \times \mathrm{RC} 2-10)$ hybrids were selected for laboratory-scale wort fermentation together with their respective parental strains. One synthetic $\mathrm{Sc} \times \mathrm{Su}$ hybrid constructed for wine fermentation, namely LS3, was added for comparative purposes. In Figure 3 and Supplementary Figure S2, fermentation profiles show that Sc $\times$ Sbay hybrids retained the fermentation performance of the best Sc parental strains, while Sc $\times$ Su hybrids exhibited an intermediate kinetic curve compared with the parents.

Growth curve analysis revealed that Sc $\times$ Sbay hybrid Y15.2B $\times$ NBRC1948 exhibited higher maximum fermentation rate $(\mu)$ and maximum fermentation level $(A)(p<0.05)$ compared with the tested strains. This hybrid fermented faster than other hybrids and slightly faster compared with the Sc parental strain Y15.2B (Figure 4).

Ethanol production ranged from $5.8 \%$ to $7.3 \% v / v$ after 12 days of fermentation at $20{ }^{\circ} \mathrm{C}$ (Supplementary Table S2). Sc $\times$ Sbay hybrids outperformed the Sc $\times$ Su hybrid in ethanol yield $(p<0.05)$. In contrast to previous studies involving ale strains crossed with S. eubayanus $[28,29,65]$, both $\mathrm{Sc} \times \mathrm{Su}$ and Sc $\times$ Sbay hybrids were intermediate in alcohol production compared with the parental strains. Sourdough strains and their hybrids with NBRC1948 yielded ethanol at more than $82 \%$ of the theoretical value. Su strains were significantly lower in viability than Sbay NBRC1948 $(p<0.05)$. 


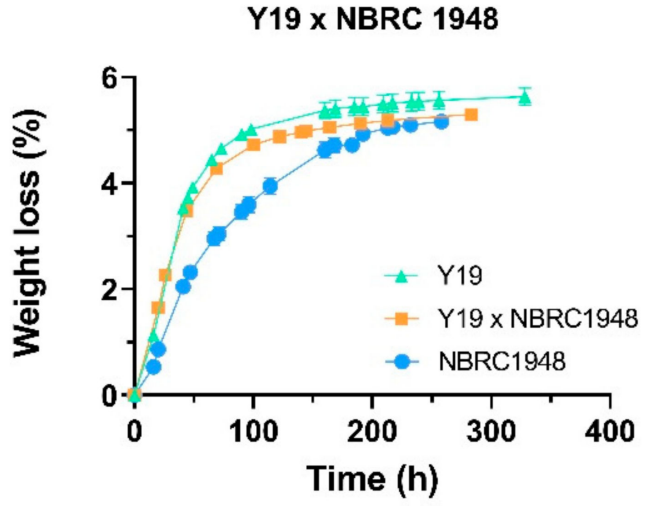

Y15.2B x NBRC 1948

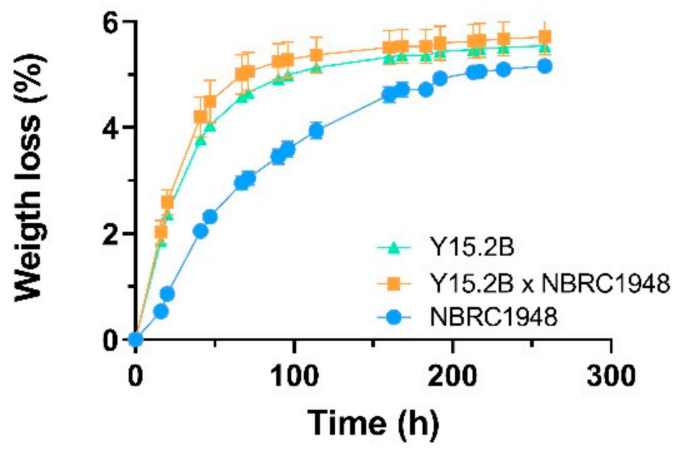

Y23 x RC2-10

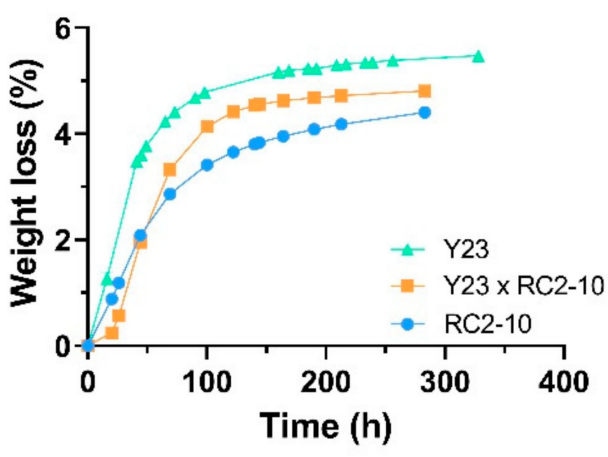

Y21 x NBRC 1948

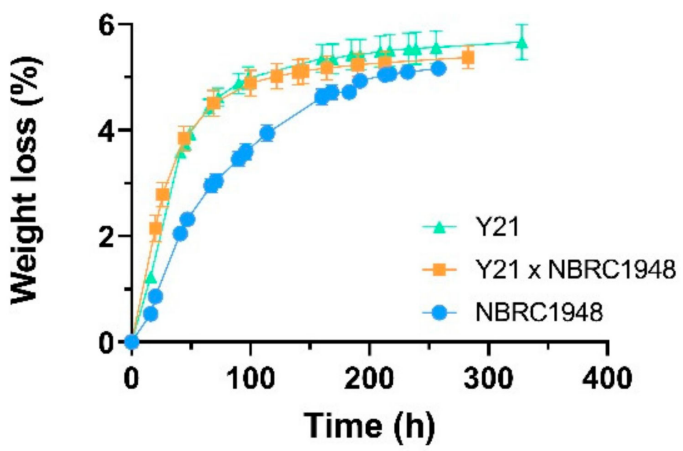

LS3

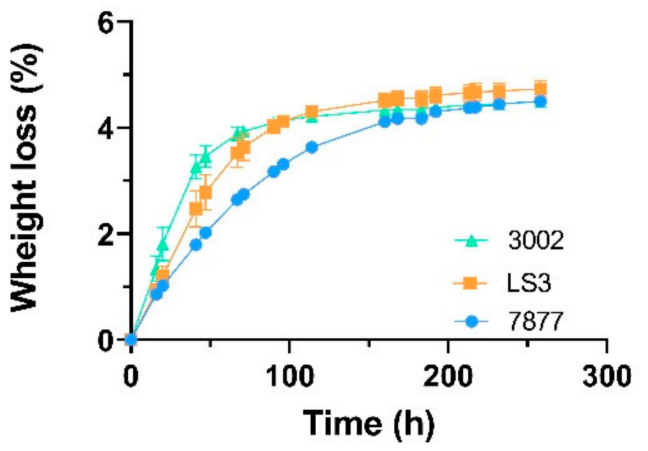

Hybrids

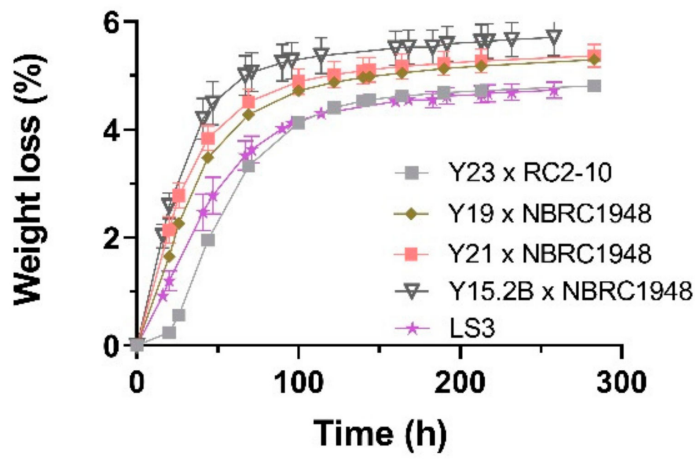

Figure 3. Growth curve plots of hybrids and their parents in wort fermentation assays at laboratory scale $\left(15^{\circ} \mathrm{P} ; 20^{\circ} \mathrm{C}\right)$. Growth kinetics were measured as weight loss percentage over time. Values are mean of three replicates. Bars represent standard deviation. 
A)

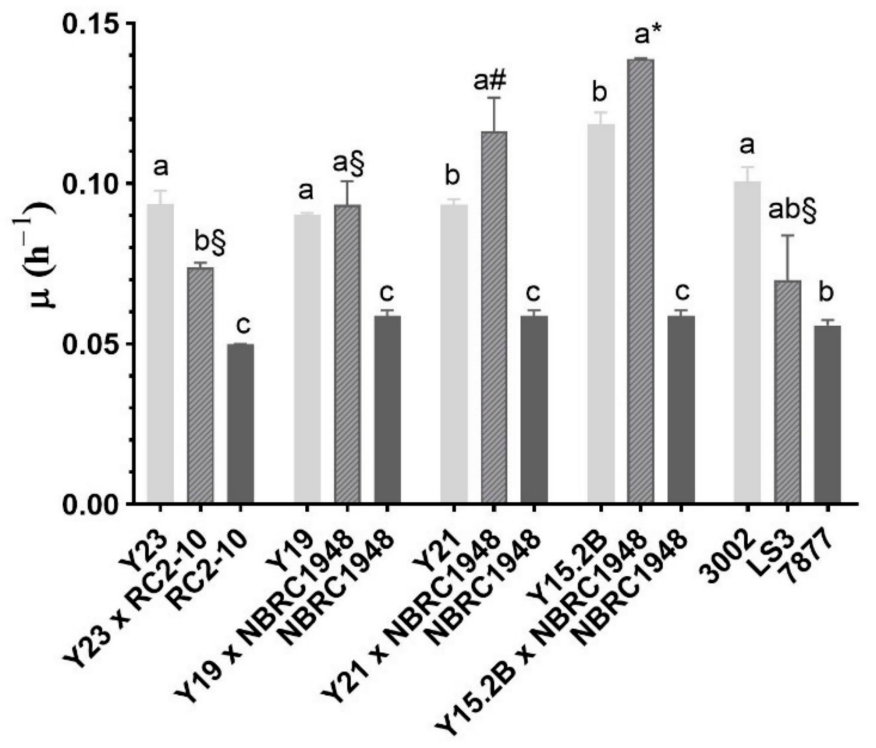

B)

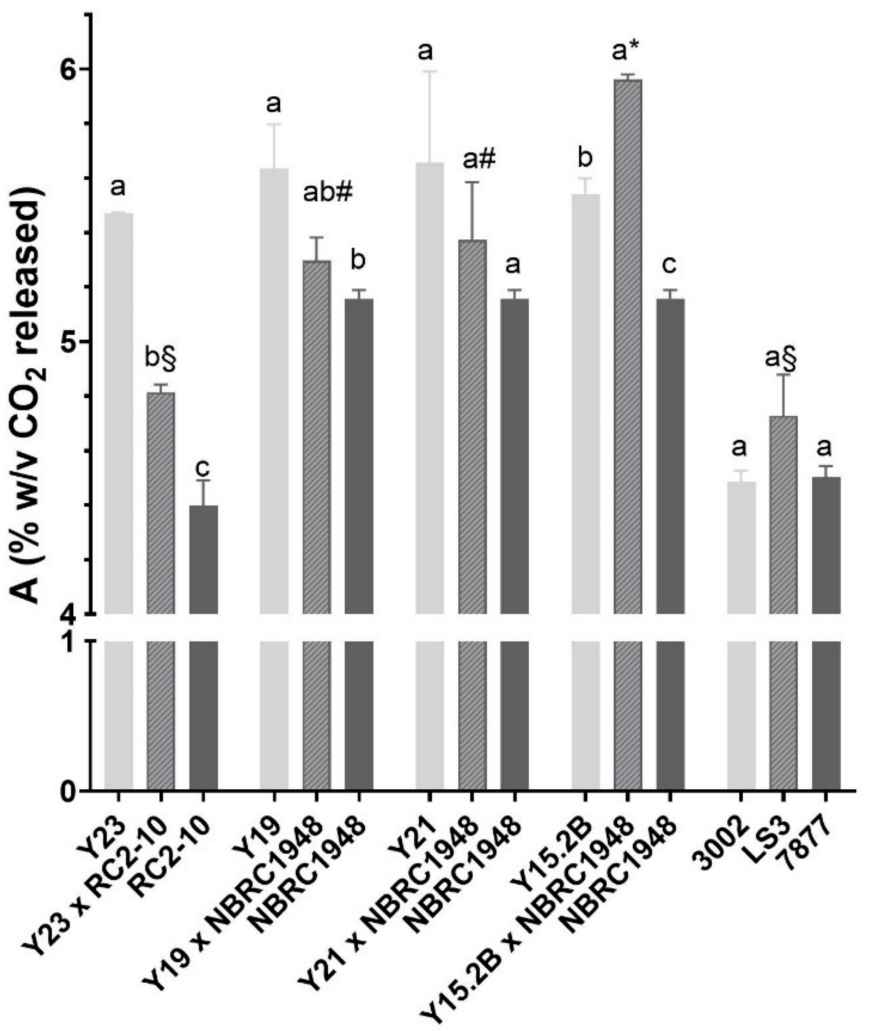

Figure 4. Values of maximum fermentation rate $\mu\left(\mathrm{h}^{-1}\right)(\mathbf{A})$ and maximum fermentation level A $\left(\% w / v \mathrm{CO}_{2}\right)(\mathbf{B})$ in laboratory-scale wort fermentation $\left(15^{\circ} \mathrm{P}, 20^{\circ} \mathrm{C}\right)$. S. cerevisiae, hybrids and S. bayanus/S. uvarum are represented as solid light gray, hatched gray and solid gray columns, respectively. Different letters indicate significant differences $(p<0.05)$ within each triad of hybrid and parents based on one-way ANOVA; different symbols (, , and *) indicate significant differences $(p<0.05)$ among hybrids Y23 $\times$ RC2-10, Y19 $\times$ NBRC1948 and Y15.2B $\times$ NBRC1948 based on oneway ANOVA. Superscript letters were attributed as follows: the highest value was marked as "a," the next value that is significantly different can be " $b$," and so on. 


\subsection{Two L-Scale Wort Fermentation}

Based on the laboratory-scale fermentation results, we selected Sc $\times$ Sbay hybrid Y15.2B $\times$ NBRC1948 for $2 \mathrm{~L}$-scale wort fermentation at $12{ }^{\circ} \mathrm{C}$. Under these conditions, the hybrid exhibited a transgressive phenotype relative to its parents; it was able to ferment efficiently the wort sugars and also to tolerate low temperatures (Figure 5), a trait that was not detectable from the previous small-scale fermentations that were carried out at the higher temperature of $20^{\circ} \mathrm{C}$.

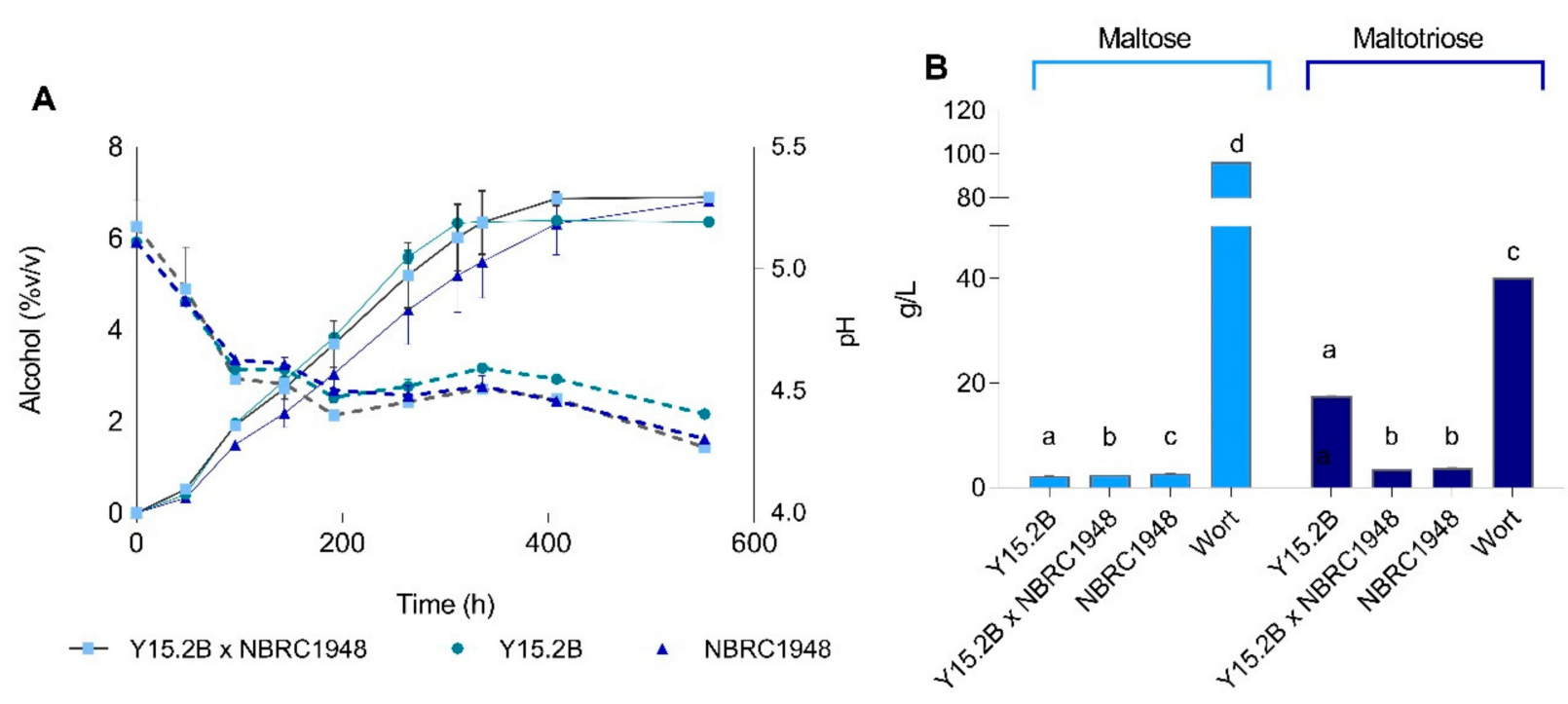

Figure 5. Wort fermentation at $2 \mathrm{~L}$-scale $\left(15^{\circ} \mathrm{P}, 12^{\circ} \mathrm{C}\right)$. Panel A exhibits trends of alcohol content $(\% v / v)($ solid line $)$ and $\mathrm{pH}$ values (dotted line) over time, while panel B reports residual sugars (maltose and maltotriose) at the end of fermentation. Values are means of two independent replicates; bars represent error range. Different letters indicate significant differences $(p<0.05)$ based on two-way ANOVA.

The S. cerevisiae parent performed relatively well in the first 10 days of fermentation, but the alcohol yield was limited in the latter stage of the fermentation, apparently due to an inability to utilize efficiently the available maltotriose, which was present in the final beer at approx. $20 \mathrm{~g} / \mathrm{L}$ (Figure 5). In contrast, the S. bayanus parent fermented more slowly, but was more efficient in terms of overall alcohol yield and sugar consumption, with residual sugar concentrations being similar to those of the hybrid strain.

The benefit of hybridization was seen not only in terms of fermentation performance, but also in beer quality. Four flavor-active aroma volatiles showed positive differences in concentration (Figure 6). Acetaldehyde, which imparts an unpleasant chemical taste to beer and is particularly noticeable in lager beers, was at the flavor threshold in the S. bayanus beer. Low levels were observed in the $S$. cerevisiae beers, as well as those beers created with the hybrid strain. 3-methylbutyl acetate, which imparts a banana or pear flavor to beer and is one of the most desirable volatile compounds, was present at concentrations above the flavor threshold in the S. cerevisiae and hybrid strain beers. The S. bayanus beer concentrations were lower than the typical flavor threshold values and are not expected to contribute in any positive way to the overall flavor profile. A similar result was found for ethyl acetate (general fruit aroma) and ethyl hexanoate (green apple, aniseed, and cherry aroma) (Figure 6). 

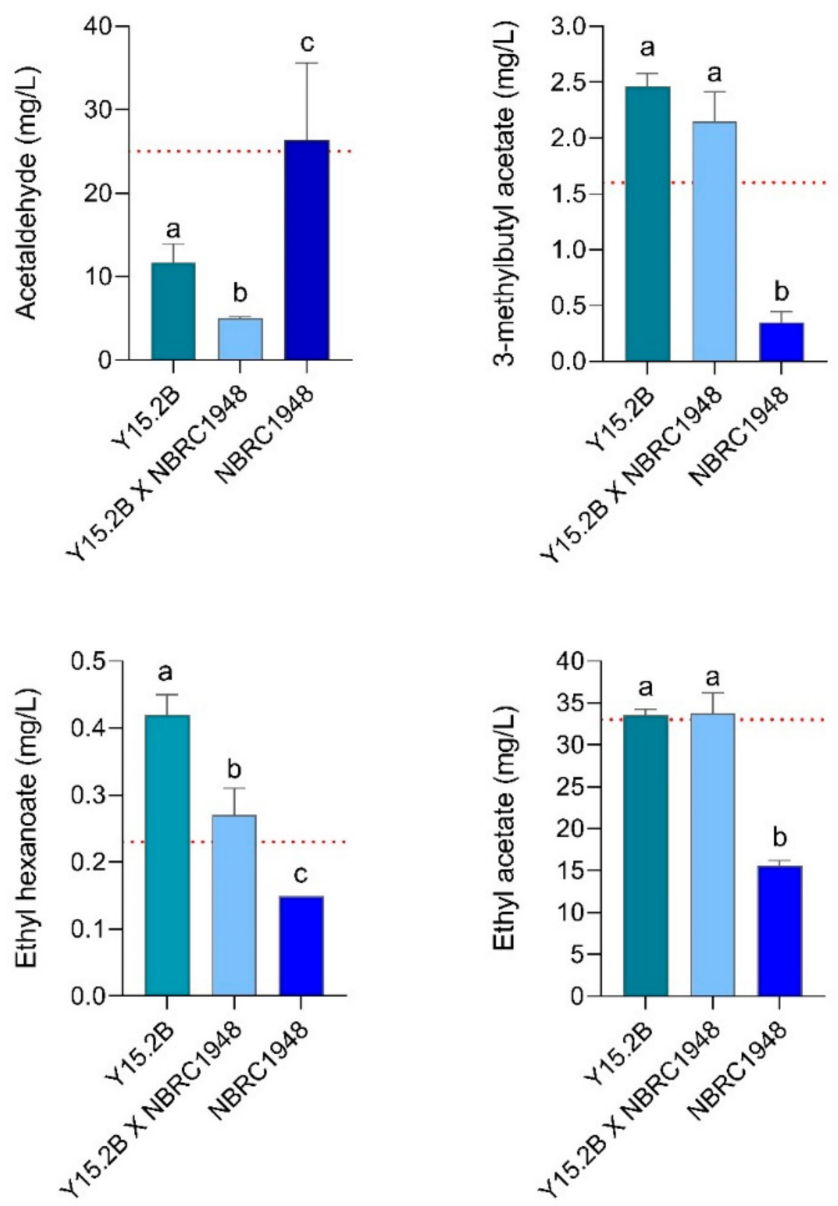

Figure 6. Concentrations of flavor-active compounds (mg/L) after $2 \mathrm{~L}$ wort fermentation $\left(15^{\circ} \mathrm{P}\right.$, $12{ }^{\circ} \mathrm{C}$ ). Values are means of two independent replicates; bars represent error range. Different superscript letters indicate significant differences $(p<0.05)$ as determined by one-way ANOVA and Tukey's test. For each compound, the relative perception threshold is reported as dotted red line [66].

\section{Discussion}

Bioprospecting efforts in brewing seek to utilize yeasts from environments other than the brewery in order to augment and/or diversify flavor properties of the final product [44]. Sourdough is a bio-reservoir of particular interest due to the occurrence of maltose-positive S. cerevisiae strains with QPS/GRAS status $[27,67]$ and potentially wellaccepted by consumers for their provenance from artisanal food systems [68]. The search for new S. cerevisiae sourdough strains as wild stocks could have great potential for wheat and other specialty beers $[40,45]$. Our sourdough strains are well-suited both for fermenting maltose and for producing flavorful molecules like ethyl- and acetate-esters [45]. However, they do not display the complete pattern of industrial adaptive signatures specific for lager brewing, making the exploitation of genetic improvement techniques mandatory. The aim of this work was to demonstrate the suitability of a phenotype-centered strategy based on outcrossing of selected strains derived from non-brewing environments for increasing genetic and phenotypic diversity of starter cultures for lager-type fermentations.

Crossbreeding between maltotriose-fermenting $S$. cerevisiae ale yeasts and cryotolerant S. non-cerevisiae species is effective for creating novel GM-free synthetic hybrids based on mating between cells with opposite mating type by using marker-assisted approaches of spore-to-spore mating, mass mating and rare mating [21,28,29,33,65]. As our sourdough strains are able to sporulate and produce viable spores, they were mated with the cryotolerant S. bayanus strain NBRC1948 to generate synthetic hybrids via a marker-less spore-to-spore mating approach. Generally, mass mating is fast procedure that is preferred 
over the spore-to-spore method and, recently, novel methods such as fluorescence-activated cell sorting (FACS) [69] were proposed for increasing and assisting marker-less hybrid recovery after rare mating. Here we demonstrated that spore-to-spore mating can produce hybrids without the requirement of any selectable phenotypes for the parental strains and at relatively high frequency if the conditions of mating have been optimized. For instance, differences in germination time may contribute to reproductive isolation between species $[51,63]$. In contrast to what was previously found in outcrossing between $S$. cerevisiae and the phylogenetically distant species $S$. uvarum, isolated spores of $S$. cerevisiae sourdough strains and S. bayanus NBRC1948 appeared to germinate almost synchronously and did not require any staggered mating. This may depend on the peculiar genetic makeup of the selected cryotolerant parent NBRC1948, which contains several introgressed $S$. cerevisiae genomic segments [46]. We also found that a prolonged exposure to starvation positively affects mating propensity of isolated spores, enhancing the recovery of Sc $\times$ Sbay hybrids. Furthermore, heterothallic parental strains or wild strains with at least one inactive copy of the $\mathrm{HO}$ gene should be preferred over homothallic yeasts for breeding as isolated spores harboring the inactive ho allele are forced to restore diploidy by outcrossing. Here, we found that all sourdough strains gave a pattern of meiotic segregants compatible with a $\mathrm{HO} /$ ho genotype. Despite homothallism representing the most common life cycle in $S$. cerevisiae $[60,70]$, heterothallic strains are frequently found in nature $[71,72]$, while heterozygous $\mathrm{HO} /$ ho strains were also isolated in industrial environments for Brazilian spirit production [73]. The extent of loss of function in $\mathrm{HO}$ genes from natural sourdough strains deserves further investigations in future. Like in other baker's yeasts [74], the $M A T$ a idiomorph prevails in meiotic segregants, suggesting two possible explanations. $M A T$ a monospore clones could be more viable than $M A T \alpha$ ones or, alternatively, sourdough strains could have a MATa/MATa/MATa/MAT $\alpha$ genotype. Overall, these results highlight the propensity of sourdough strains for outcrossing and provide some guidelines for optimizing successful outcrosses in spore-to-spore mating experiments without any GM technology utilized.

Evaluation of the hybrids under lager brewing conditions clearly showed the potential of the $S$. cerevisiae $\times S$. bayanus hybrid combination for industrial application. With one particular parental combination, the hybrid benefited from increased maltotriose utilization and higher concentration of esters in the resultant beers. While yeast hybrids occur in both natural and industrial environments [14,15,75-77], they appear to be more common (or more persistent) in the latter. This suggests that the hybrid state confers a distinct advantage in such environments. Recent work involving artificially created hybrids has confirmed this suggestion, with newly created hybrids showing promise for application in a number of fermentation environments including beer, cider, and wine production [24,29,35,78-80]. The de novo creation of lager yeast hybrids has been of particular interest due to the commercial importance of the S. pastorianus lager yeast and the low level of diversity within this group. Recreation of the $S$. cerevisiae $\times$ S. eubayanus hybrid has shown clearly that the success of $S$. pastorianus under low-temperature wort brewing conditions was due to two-parent transgression. The hybrid benefited from the superior ability of $S$. cerevisiae to utilize wort sugars (particularly maltotriose), and the psychrotolerance of $S$. eubayanus. Hybrids therefore had a competitive advantage over both ale yeasts and wild Saccharomyces yeasts when fermenting wort at low temperature [28]. The advantage is, however, not necessarily parent-species specific; any combination of species that introduces the required phenotypes should be effective. Nikulin et al. [33], for example, created yeasts with a lager yeast phenotype by combining $S$. cerevisiae with yeasts other than $S$. eubayanus. Saccharomyces mikatae, for example, was equally effective at transferring the cold-tolerant phenotype to the hybrid. There is therefore scope for creating yeasts with industry-relevant phenotypes without recapitulating the original species combination [81]. The example in the present study is the first to show that a yeast with a phenotype suitable for brewing can be created even when neither parent has been used as production strain for brewing. 
This phenotype-centered approach to parent selection increases the genetic diversity that may be tapped for hybrid design.

Previous attempts to create lager hybrids have utilized S. cerevisiae as the maltose-, and maltotriose-positive partner [28]. Of note here was the finding that the S. bayanus parent appeared to be more adept at wort sugar utilization than the S. cerevisiae parent. This, at first, may seem counterintuitive, given that maltotriose utilization is not typical for either of the species (S. eubayanus or S. uvarum) included in the species complex [33]. However, the S. bayanus strain utilized in this study (NBRC1948) is known to possess a considerable amount of $S$. cerevisiae-introgressed DNA and, in particular, a large $(70 \mathrm{~kb})$ region containing the maltose transporter gene $M A L 31$, and the maltose and maltotriose transporter gene (MTY1/MTT1). These genes and a number of other S. cerevisiae-derived genes related to osmotic stress resistance, anaerobic growth, and sucrose utilization may have been key to the survival of this strain as a contaminant in a brewery environment (the original source of the strain) [40]. This same introgression is feasibly responsible for the improved brewing efficiency of the hybrid created in this study. It is perhaps significant here that the Mtt1 transporter is known to have a high affinity for maltotriose relative to other transporters [82], and this may explain the greater ability to consume the trisaccharide during fermentation. It may be hypothesized that the sourdough $S$. cerevisiae parent possesses a lower affinity transporter such as Malx1. It has also been found that the Mtt1 transporter performs well at low temperature relative to other yeast maltotriose transporters [83].

In conclusion, this study proves that synthetic triple hybrids involving phenotypebased selection of non-brewing parents could be useful for diversification of lager yeast stock cultures. Outcrossing experiments defined environmental conditions that optimize hybrid recovery without any utilization of auxotrophic marker and/or GM techniques. In being an S. eubayanus x S. uvarum hybrid, strain NBRC1948 exhibits cold-tolerance, but is also able to ferment maltotriose better than S. eubayanus due to the presence of MTY1/MTT1, a gene encoding the cold-tolerant maltotriose transporter described in S. pastorianus $[82,84]$. S. cerevisiae sourdough strains have good fermentative aptitude in wort and positively affect aroma profile, a phenotype that is positively inherited by hybrids. Phenotype-driven selection of parents followed by outcrossing is a promising biotechnological solution that combines different benefit phenotypes into a single brewing culture.

Supplementary Materials: The following are available online at https:/ / www.mdpi.com/2076-260 7/9/3/514/s1. Figure S1: Confirmation of hybridization by (A) ITS1 PCR-RFLP with endonuclease HaeIII and (B) amplification of FSY1 and MEX67 genes using species-specific primers; Figure S2: Correlations plots between expected and actual values of ethanol concentrations (A) and yeast dry matter (B); Table S1: Hybrid sporulation assay. Table S2: Wort fermentation parameters in laboratory scale trials $\left(15^{\circ} \mathrm{P}, 20^{\circ} \mathrm{C}\right)$.

Author Contributions: Conceptualization, L.S.; formal analysis, C.L.R. and C.C.; investigation, F.I, F.M., K.K., and M.C.; data curation, L.S.; writing-original draft preparation, L.S.; writing-review and editing, L.S., B.G., K.K., F.M., C.L.R. and C.C.; supervision, B.G. All authors have read and agreed to the published version of the manuscript.

Funding: L.S. was supported by the Italian Ministry of Education, University and Research (MIUR), within the framework of the Italian National Grant for Fundamental Research (FFABR 2017).

Institutional Review Board Statement: Not applicable.

Informed Consent Statement: Not applicable.

Data Availability Statement: Data sharing not applicable.

Conflicts of Interest: The authors declare no conflict of interest. Kristoffer Krogerus and Frederico Magalhães are from VTT Technical Research Centre of Finland Ltd., the company had no role in the design of the study; in the collection, analyses, or interpretation of data; in the writing of the manuscript, or in the decision to publish the results. 


\section{References}

1. Abbott, R.; Albach, D.; Ansell, S.; Arntzen, J.W.; Baird, S.J.E.; Bierne, N.; Boughman, J.; Brelsford, A.; Buerkle, C.A.; Buggs, R.; et al. Hybridization and speciation. J. Evol. Biol. 2013, 26, 229-246. [CrossRef]

2. Scannell, D.R.; Butler, G.; Wolfe, K.H. Yeast genome evolution-The origin of the species. Yeast 2007, 24, 929-942. [CrossRef] [PubMed]

3. Fridman, E. Consequences of hybridization and heterozygosity on plant vigor and phenotypic stability. Plant Sci. 2015, 232, 35-40. [CrossRef] [PubMed]

4. Wu, C.I.; Ting, C.T. Genes and speciation. Nat. Rev. Genet. 2004, 5, 114-122. [CrossRef]

5. Dagilis, A.J.; Kirkpatrick, M.; Bolnick, D.I. The evolution of hybrid fitness during speciation. PLoS Genet. 2019, 15, e1008125. [CrossRef] [PubMed]

6. Bell, M.A.; Travis, M.P. Hybridization, transgressive segregation, genetic covariation, and adaptive radiation. Trends Ecol. Evol. 2005, 20, 358-361. [CrossRef] [PubMed]

7. Steinmetz, L.M.; Sinha, H.; Richards, D.R.; Spiegelman, J.I.; Oefner, P.J.; McCusker, J.H.; Davis, R.W. Dissecting the architecture of a quantitative trait locus in yeast. Nature 2002, 416, 326-330. [CrossRef]

8. Libkind, D.; Hittinger, C.T.; Valério, E.; Gonçalves, C.; Dover, J.; Johnston, M.; Gonçalves, P.; Sampaio, J.P. Microbe domestication and the identification of the wild genetic stock of lager-brewing yeast. Proc. Natl. Acad. Sci. USA 2011, 108, 14539-14544. [CrossRef]

9. Kellis, M.; Patterson, N.; Endrizzi, M.; Birren, B.; Lander, E.S. Sequencing and comparison of yeast species to identify genes and regulatory elements. Nature 2003, 423, 241-254. [CrossRef]

10. Hittinger, C.T. Saccharomyces diversity and evolution: A budding model genus. Trends Genet. 2013, 29, 309-317. [CrossRef]

11. Sipiczki, M. Interspecies hybridization and recombination in Saccharomyces wine yeasts. FEMS Yeast Res. 2008, 8, 996-1007. [CrossRef]

12. Albertin, W.; Marullo, P. Polyploidy in fungi: Evolution after whole-genome duplication. Proc. R. Soc. B Biol. Sci. 2012, 279, 2497-2509. [CrossRef] [PubMed]

13. Morales, L.; Dujon, B. Evolutionary role of interspecies hybridization and genetic exchanges in yeasts. Microbiol. Mol. Biol. Rev. 2012, 76, 721-739. [CrossRef] [PubMed]

14. Gallone, B.; Steensels, J.; Mertens, S.; Dzialo, M.C.; Gordon, J.L.; Wauters, R.; Theßeling, F.A.; Bellinazzo, F.; Saels, V.; HerreraMalaver, B.; et al. Interspecific hybridization facilitates niche adaptation in beer yeast. Nat. Ecol. Evol. 2019, 3, $1562-1575$. [CrossRef] [PubMed]

15. Langdon, Q.K.; Peris, D.; Baker, E.P.; Opulente, D.A.; Nguyen, H.V.; Bond, U.; Gonçalves, P.; Sampaio, J.P.; Libkind, D.; Hittinger, C.T. Fermentation innovation through complex hybridization of wild and domesticated yeasts. Nat. Ecol. Evol. 2019, 3, 1576-1586. [CrossRef]

16. de Barros Lopes, M.; Bellon, J.R.; Shirley, N.J.; Ganter, P.F. Evidence for multiple interspecific hybridization in Saccharomyces sensu stricto species. FEMS Yeast Res. 2002, 1, 323-331. [CrossRef]

17. Dunn, B.; Sherlock, G. Reconstruction of the genome origins and evolution of the hybrid lager yeast Saccharomyces pastorianus. Genome Res. 2008, 18, 1610-1623. [CrossRef]

18. Liti, G.; Barton, D.B.H.; Louis, E.L. Sequence diversity, reproductive isolation and species concepts in Saccharomyces. Genetics 2006, 174, 839-850. [CrossRef]

19. Nakao, Y.; Kanamori, T.; Itoh, T.; Kodama, Y.; Rainieri, S.; Nakamura, N.; Shimonaga, T.; Hattori, M.; Ashikari, T. Genome sequence of the lager brewing yeast, an interspecies hybrid. DNA Res. 2009, 16, 115-129. [CrossRef]

20. Walther, A.; Hesselbart, A.; Wendland, J. Genome sequence of Saccharomyces carlsbergensis, the world's first pure culture lager yeast. G3 (Bethesda) 2014, 4, 783-793. [CrossRef]

21. Hebly, M.; Brickwedde, A.; Bolat, I.; Driessen, M.; de Hulster, E.; van den Broek, M.; Pronk, J.; Geertman, J.; Daran, J.; DaranLapujade, P. S. cerevisiae $\times$ S. eubayanus interspecific hybrid, best of both worlds and beyond. FEMS Yeast Res. 2015, 15, fov005. [CrossRef]

22. Gibson, B.R.; Storgårds, E.; Krogerus, K.; Vidgren, V. Comparative physiology and fermentation performance of Saaz and Frohberg lager yeast strains and the parental species Saccharomyces eubayanus. Yeast 2013, 30, 255-266. [CrossRef]

23. Brouwers, N.; Brickwedde, A.; de Vries, A.R.G.; van den Broek, M.; Weening, S.M.; van den Eijnden, L.; Diderich, J.A.; Bai, F.Y.; Pronk, J.T.; Daran, J.G. The genome sequences of Himalayan Saccharomyces eubayanus revealed genetic markers explaining heterotic maltotriose consumption by hybrid Saccharomyces pastorianus. Appl. Environ. Microbiol. 2019, 85, e01516-e01519. [CrossRef] [PubMed]

24. Magalhães, F.; Vidgren, V.; Ruohonen, L.; Gibson, B. Maltose and maltotriose utilisation by group I strains of the hybrid lager yeast Saccharomyces pastorianus. FEMS Yeast Res. 2016, 16. [CrossRef]

25. Okuno, M.; Kajitani, R.; Ryusui, R.; Morimoto, H.; Kodama, Y.; Itoh, T. Next-generation sequencing analysis of lager brewing yeast strains reveals the evolutionary history of interspecies hybridization. DNA Res. 2016, 23, 67-80. [CrossRef]

26. Salazar, A.N.; de Vries, A.R.G.; van den Broek, M.; Brouwers, N.; de la Torre Cortès, P.; Kuijpers, N.G.A.; Daran, J.-M.G.; Abeel, T. Chromosome level assembly and comparative genome analysis confirm lager-brewing yeasts originated from a single hybridization. BMC Genom. 2019, 20, 916. [CrossRef] 
27. Iattici, F.; Catallo, M.; Solieri, L. Designing new yeasts for craft brewing: When natural biodiversity meets biotechnology. Beverages 2020, 6, 3. [CrossRef]

28. Krogerus, K.; Magalhães, F.; Vidgren, V.; Gibson, B. New lager yeast strains generated by interspecific hybridization. J. Ind. Microbiol. Biotechnol. 2015, 42, 769-778. [CrossRef] [PubMed]

29. Mertens, S.; Steensels, J.; Saels, V.; De Rouck, G.; Aerts, G.; Verstrepen, K.J. A large set of newly created interspecific yeast hybrids increases aromatic diversity in lager beers. Appl. Environ. Microbiol. 2015, 81, 8202-8214. [CrossRef]

30. Peris, D.; Sylvester, K.; Libkind, D.; Gonçalves, P.; Sampaio, J.P.; Alexander, W.G.; Hittinger, C.T. Population structure and reticulate evolution of Saccharomyces eubayanus and its lager-brewing hybrids. Mol. Ecol. 2014, 23, 2031-2045. [CrossRef] [PubMed]

31. Bing, J.; Han, P.J.; Liu, W.Q.; Wang, Q.M.; Bai, F.Y. Evidence for a Far East Asian origin of lager beer yeast. Curr. Biol. 2014, 24, R380-R381. [CrossRef]

32. Gayevskiy, V.; Goddard, M.R. Saccharomyces eubayanus and Saccharomyces arboricola reside in North Island native New Zealand forests. Environ. Microbiol. 2015, 18, 1137-1147. [CrossRef] [PubMed]

33. Nikulin, J.; Krogerus, K.; Gibson, B. Alternative Saccharomyces interspecies hybrid combinations and their potential for lowtemperature wort fermentation. Yeast 2018, 35, 113-127. [CrossRef] [PubMed]

34. Gunge, N.; Nakatomi, Y. Genetic mechanisms of rare matings of the yeast Saccharomyces cerevisiae heterozygous for mating type. Genetics 1972, 70, 41-58. [CrossRef] [PubMed]

35. Krogerus, K.; Seppänen-Laakso, T.; Castillo, S.; Gibson, B. Inheritance of brewing-relevant phenotypes in constructed Saccharomyces cerevisiae $\times$ Sacharomyces eubayanus hybrids. Microb. Cell Fact. 2017, 16, 1-22. [CrossRef]

36. Lenz, S.D.; Riles, L.; Fay, J.C. Heterochronic meiotic misexpression in an interspecific yeast hybrid. Mol. Biol. Evol. 2014, 31, 1333-1342. [CrossRef] [PubMed]

37. Tirosh, I.; Reikhav, S.; Levy, A.A.; Barkai, N. A yeast hybrid provides insight into the evolution of gene expression regulation. Science 2009, 324, 659-662. [CrossRef] [PubMed]

38. Alexander, W.G.; Peris, D.; Pfannenstiel, B.T.; Opulente, D.; Kuang, M.; Hittinger, C.T. Efficient engineering of marker-free synthetic allotetraploids of Saccharomyces. Fungal Genet. Biol. 2016, 89, 10-17. [CrossRef]

39. Peris, D.; Alexander, W.G.; Fisher, K.J.; Moriarty, R.V.; Basuino, M.G.; Ubbelohde, E.J.; Wrobel, R.L.; Hittinger, C.T. Synthetic hybrids of six yeast species. Nat. Commun. 2020, 11, 1-11. [CrossRef]

40. Marongiu, A.; Zara, G.; Legras, J.-L.; Del Caro, A.; Mascia, I.; Fadda, C.; Budroni, M. Novel starters for old processes: Use of Saccharomyces cerevisiae strains isolated from artisanal sourdough for craft beer production at a brewery scale. J. Ind. Microbiol. Biotechnol. 2015, 42, 85-92. [CrossRef]

41. da Conceição, L.; Saraiva, M.; Diniz, R.; Oliveira, J.; Barbosa, G.; Alvarez, F.; da Mata Correa, L.; Mezadri, H.; Coutrim, M.; Afonso, R.; et al. Biotechnological potential of yeast isolates from cachaça: The Brazilian spirit. J. Ind. Microbiol. Biotechnol. 2015, 42, 237-246. [CrossRef]

42. Araújo, T.M.; Souza, M.T.; Diniz, R.H.S.; Yamakawa, C.K.; Soares, L.B.; Lenczak, J.L.; de Castro Oliveira, J.V.; Goldman, G.H.; Barbosa, E.A.; Campos, A.C.S.; et al. Cachaça yeast strains: Alternative starters to produce beer and bioethanol. Antonie Van Leeuwenhoek 2018, 111, 1749-1766. [CrossRef]

43. Rossi, S.; Turchetti, B.; Sileoni, V.; Marconi, O.; Perretti, G. Evaluation of Saccharomyces cerevisiae strains isolated from non-brewing environments in beer production. J. Inst. Brew. 2018, 124, 381-388. [CrossRef]

44. Cubillos, F.A.; Gibson, B.; Grijalva-Vallejos, N.; Krogerus, K.; Nikulin, J. Bioprospecting for brewers: Exploiting natural diversity for naturally diverse beers. Yeast 2019, 36, 383-398. [CrossRef]

45. Catallo, M.; Nikulin, J.; Johansson, L.; Krogerus, K.; Laitinen, M.; Magalhães, F.; Piironen, M.; Mikkelson, A.; Randazzo, C.L.; Solieri, L.; et al. Sourdough derived strains of Saccharomyces cerevisiae and their potential for farmhouse ale brewing. J. Inst. Brew. 2020. [CrossRef]

46. Nguyen, H.-V.; Legras, J.-L.; Neuvéglise, C.; Gaillardin, C. Deciphering the hybridization history leading to the lager lineage based on the mosaic genomes of Saccharomyces bayanus strains NBRC1948 and CBS380 ${ }^{\mathrm{T}}$. PLoS ONE 2011, 6, e25821. [CrossRef]

47. Pérez-Través, L.; Lopes, C.A.; Querol, Q.; Barrio, B. On the complexity of the Saccharomyces bayanus taxon: Hybridization and potential hybrid speciation. PLoS ONE 2014, 9, e93729. [CrossRef]

48. Giudici, P.; Restuccia, C.; Randazzo, C.; Melia, V.; Corte, V. Biodiversità fenotipica di lieviti isolati da mosti cotti e vini siciliani. Ind. Bevande 1990, 26, 252-259.

49. Solieri, L.; Antúnez, O.; Pérez-Ortín, J.E.; Barrio, E.; Giudici, P. Mitochondrial inheritance and fermentative: Oxidative balance in hybrids between Saccharomyces cerevisiae and Saccharomyces uvarum. Yeast 2008, 25, 485-500. [CrossRef] [PubMed]

50. Kurtzman, C.P.; Fell, J.W.; Boekhout, T.; Robert, R. Methods for Isolation, Phenotypic Characterization and Maintenance of Yeasts. In The Yeasts: A Taxonomic Study, 5th ed.; Kurtzman, C.P., Fell, W.F., Boekhout, T., Eds.; Elsevier: Amsterdam, The Netherlands, 2011; Volume 1, pp. 87-110.

51. Murphy, H.A.; Zeyl, C.W. Prezygotic isolation between Saccharomyces cerevisiae and Saccharomyces paradoxus through differences in mating speed and germination timing. Evolution 2012, 66, 1196-1209. [CrossRef] [PubMed]

52. Lõoke, M.; Kristjuhan, K.; Kristjuhan, A. Extraction of genomic DNA from yeasts for PCR-based applications. BioTechniques 2011, 50, 325-328. [CrossRef]

53. Huxley, C.; Green, E.D.; Dunham, I. Rapid assessment of S. cerevisiae mating type by PCR. Trends Genet. 1990, 6, 236. 
54. Solieri, L.; Verspohl, A.; Bonciani, T.; Caggia, C.; Giudici, P. Fast method for identifying inter- and intra-species Saccharomyces hybrids in extensive genetic improvement programs based on yeast breeding. J. Appl. Microbiol. 2015, 119, 149-161. [CrossRef]

55. Pengelly, R.J.; Wheals, A.E. Rapid identification of Saccharomyces eubayanus and its hybrids. FEMS Yeast Res. 2013, 13, 156-161. [CrossRef]

56. Dakal, T.C.; Solieri, L.; Giudici, P. Evaluation of fingerprinting techniques to assess genotype variation among Zygosaccharomyces strains. Food Microbiol. 2018, 72, 135-145. [CrossRef]

57. Krogerus, K.; Holmström, S.; Gibson, B. Enhanced wort fermentation with de novo lager hybrids adapted to high-ethanol environments. Appl. Environ. Microbiol. 2019, 84, e02302-e02317. [CrossRef]

58. Kahm, M.; Hasenbrink, G.; Lichtenberg-Frate, H.; Ludwig, J.; Kschischo, M. Grofit: Fitting biological growth curves. J. Stat. Softw. 2010, 33, 1-21. [CrossRef]

59. Oura, E.; Suomalainen, H.; Viskari, R. Breadmaking. In Economic Microbiology; Rose, A.H., Ed.; Academic Press: London, UK, 1982; pp. 512-546.

60. Zastrow, C.; Hollatz, C.; De Araujo, P.; Stambuk, B. Maltotriose fermentation by Saccharomyces cerevisiae. J. Ind. Microbiol. Biotechnol. 2001, 27, 34-38. [CrossRef]

61. Mortimer, R.K. Evolution and variation of the yeast (Saccharomyces) genome. Genome Res. 2000, 10, 403-409. [CrossRef]

62. Steensels, J.; Snoek, T.; Meersman, E.; Nicolino, M.P.; Voordeckers, K.; Verstrepen, K.J. Improving industrial yeast strains: Exploiting natural and artificial diversity. FEMS Microbiol. Rev. 2014, 38, 947-995. [CrossRef]

63. Maclean, C.J.; Greig, D. Prezygotic reproductive isolation between Saccharomyces cerevisiae and Saccharomyces paradoxus. BMC Evol. Biol. 2008, 8, 1. [CrossRef]

64. Verspohl, A.; Pignedoli, S.; Giudici, P. The inheritance of mitochondrial DNA in interspecific Saccharomyces hybrids and their properties in winemaking. Yeast 2018, 35, 173-187. [CrossRef] [PubMed]

65. Krogerus, K.; Magalhães, F.; Vidgren, V.; Gibson, B. Novel brewing yeast hybrids: Creation and application. Appl. Microbiol. Biotechnol. 2017, 101, 65-78. [CrossRef] [PubMed]

66. Meilgaard, M.C. Flavor chemistry of beer. II. Flavor and threshold of 239 aroma volatiles. Technol. Quart. Master. Brew. Assoc. Am. $1975,12,151-168$.

67. Koutsoumanis, K.; Allende, A.; Álvarez-Ordóñez, A.; Bolton, D.; Bover-Cid, S.; Chemaly, M.; Davies, R.; Hilbert, F.; Lindqvist, R.; Nauta, M. Update of the list of QPS-recommended biological agents intentionally added to food or feed as notified to EFSA 9: Suitability of taxonomic units notified to EFSA until September 2018. Efsa J. 2019, 17, e05555.

68. Capozzi, V.; Fragasso, M.; Russo, P. Microbiological safety and the management of microbial resources in artisanal foods and beverages: The need for a transdisciplinary assessment to conciliate actual trends and risks avoidance. Microorganisms 2020, 8 , 306. [CrossRef]

69. de Vries, A.R.G.; Koster, C.C.; Weening, S.M.; Luttik, M.A.H.; Kuijpers, N.G.A.; Geertman, J.-M.A.; Pronk, J.T.; Daran, J.-M.G. Phenotype-independent isolation of interspecies Saccharomyces hybrids by dual-dye fluorescent staining and fluorescenceactivated cell sorting. Front. Microbiol. 2019, 10, 871. [CrossRef]

70. Butler, G.; Kenny, C.; Fagan, A.; Kurischko, C.; Gaillardin, C.; Wolfe, K.H. Evolution of the MAT locus and its Ho endonuclease in yeast species. Proc. Natl. Acad. Sci. USA 2004, 101, 1632-1637. [CrossRef]

71. Katz Ezov, T.; Chang, S.L.; Frenkel, Z.; Segrè, A.V.; Bahalul, M.; Murray, A.W.; Leu, J.Y.; Korol, A.; Kashi, Y. Heterothallism in Saccharomyces cerevisiae isolates from nature: Effect of HO locus on the mode of reproduction. Mol. Ecol. 2010, 19, 121-131. [CrossRef] [PubMed]

72. Fischer, G.; Liti, G.; Llorente, B. The budding yeast life cycle: More complex than anticipated? Yeast 2021, 38. [CrossRef]

73. Figueiredo, B.I.C.; Saraiva, M.A.F.; de Souza Pimenta, P.P.; de Souza Testasicca, M.C.; Sampaio, G.M.S.; da Cunha, A.C.; Afonso, L.C.C.; de Queiroz, M.V.; de Miranda Castro, I.; Brandao, R.L. New lager brewery strains obtained by crossing techniques using cachaça (Brazilian spirit) yeasts. Appl. Environ. Microbiol. 2017, 83. [CrossRef]

74. Korhola, M.; Naumova, E.S.; Partti, E.; Aittamaa, M.; Turakainen, H.; Naumov, G.I. Exploiting heterozygosity in industrial yeasts to create new and improved baker's yeasts. Yeast 2019, 36, 571-587. [CrossRef]

75. Barbosa, R.; Almeida, P.; Safar, S.V.; Santos, R.O.; Morais, P.B.; Nielly-Thibault, L.; Leducq, J.-B.; Landry, C.R.; Gonçalves, P.; Rosa, C.A.; et al. Evidence of natural hybridization in Brazilian wild lineages of Saccharomyces cerevisiae. Genome Biol. Evol. 2016, 8, 317-329. [CrossRef] [PubMed]

76. Pontes, A.; Čadež, N.; Gonçalves, P.; Sampaio, J.P. A quasi-domesticate relic hybrid population of Saccharomyces cerevisiae $\times$ S paradoxus adapted to olive brine. Front. Genet. 2019, 10, 449. [CrossRef] [PubMed]

77. D'Angiolo, M.; De Chiara, M.; Yue, J.-X.; Irizar, A.; Stenberg, S.; Persson, K.; Llored, A.; Barré, B.; Schacherer, J.; Marangoni, R.; et al. A yeast living ancestor reveals the origin of genomic introgressions. Nature 2020, 587, 420-425. [CrossRef]

78. Bellon, J.R.; Schmid, F.; Capone, D.L.; Dunn, B.L.; Chambers, P.J. Introducing a new breed of wine yeast: Interspecific hybridization between a commercial Saccharomyces cerevisiae wine yeast and Saccharomyces mikatae. PLoS ONE 2013, 8, e62053. [CrossRef] [PubMed]

79. Origone, A.C.; Rodríguez, M.E.; Oteiza, J.M.; Querol, A.; Lopes, C.A. Saccharomyces cerevisiae $\times$ Saccharomyces uvarum hybrids generated under different conditions share similar winemaking features. Yeast 2018, 35, 157-171. [CrossRef]

80. Kanter, J.P.; Benito, S.; Brezina, S.; Beisert, B.; Fritsch, S.; Patz, C.D.; Rauhut, D. The impact of hybrid yeasts on the aroma profile of cool climate Riesling wines. Food Chem. X 2020, 5, 100072. [CrossRef] 
81. Krogerus, K.; Preiss, R.; Gibson, B. A unique Saccharomyces cerevisiae $\times$ Saccharomyces uvarum hybrid isolated from Norwegian farmhouse beer: Characterization and reconstruction. Front. Microbiol. 2018, 9, 2253. [CrossRef]

82. Dietvorst, J.; Londesborough, J.; Steensma, H.Y. Maltotriose utilization in lager yeast strains: MTT1 encodes a maltotriose transporter. Yeast 2005, 22, 775-788. [CrossRef]

83. Vidgren, V.; Multanen, J.-P.; Ruohonen, L.; Londesborough, J. The temperature dependence of maltose transport in ale and lager strains of brewer's yeast. FEMS Yeast Res. 2010, 10, 402-411. [CrossRef] [PubMed]

84. Salema-Oom, M.; Pinto, V.V.; Goncalves, P.; Spencer-Martins, I. Maltotriose utilization by industrial Saccharomyces strains: Characterization of a new member of the $\alpha$-glucoside transporter family. Appl. Environ. Microbiol. 2005, 71, 5044-5049. [CrossRef] 